\title{
CAMA
}

Centre for Applied Macroeconomic Analysis

\section{Investigating a measure of conventional and unconventional stimulus for the euro area}

\section{CAMA Working Paper 27/2021 March 2021}

\section{Arne Halberstadt}

Deutsche Bundesbank

\section{Leo Krippner}

Reserve Bank of New Zealand

Centre for Applied Macroeconomic Analysis, ANU

\section{Abstract}

We investigate the effect of the "Effective Monetary Stimulus" (EMS) on German and euro-area macroeconomic variables using a small-scale vector autoregression (VAR). The EMS is obtained from yield curve data and survey data, and is designed to reflect the influence of monetary policy conducted by conventional and unconventional means. Empirically, using the EMS in our VAR obtains plausible and stable structural relationships with inflation and economic activity across and within conventional and unconventional environments, and more so than short-maturity rates or alternative metrics. These results suggest that the EMS provides a useful practical measure of monetary/financial stimulus for policy makers. Our counterfactual results indicate that EMS shocks have been stimulatory for most of the time since 2007, and more so around episodes of unconventional policy actions by the ECB. In turn, these episodes have been followed by higher outcomes of inflation and economic activity. 


\title{
Keywords
}

Monetary Policy, Zero Lower Bound, Dynamic Term Structure Model.

\author{
JEL Classification
}

E43, E44, E52

\section{Address for correspondence:}

(E) cama.admin@anu.edu.au

ISSN 2206-0332

The Centre for Applied Macroeconomic Analysis in the Crawford School of Public Policy has been established to build strong links between professional macroeconomists. It provides a forum for quality macroeconomic research and discussion of policy issues between academia, government and the private sector.

The Crawford School of Public Policy is the Australian National University's public policy school, serving and influencing Australia, Asia and the Pacific through advanced policy research, graduate and executive education, and policy impact. 


\title{
Investigating a measure of conventional and
}

\section{unconventional stimulus for the euro area*}

\author{
Arne Halberstadt Leo Krippner
}

\begin{abstract}
We investigate the effect of the "Effective Monetary Stimulus" (EMS) on German and euro-area macroeconomic variables using a small-scale vector autoregression (VAR). The EMS is obtained from yield curve data and survey data, and is designed to reflect the influence of monetary policy conducted by conventional and unconventional means. Empirically, using the EMS in our VAR obtains plausible and stable structural relationships with inflation and economic activity across and within conventional and unconventional environments, and more so than shortmaturity rates or alternative metrics. These results suggest that the EMS provides a useful practical measure of monetary/financial stimulus for policy makers. Our counterfactual results indicate that EMS shocks have been stimulatory for most of the time since 2007, and more so around episodes of unconventional policy actions by the ECB. In turn, these episodes have been followed by higher outcomes of inflation and economic activity.
\end{abstract}

Keywords: Monetary Policy, Zero Lower Bound, Dynamic Term Structure Model.

JEL classification: E43, E44, E52.

*Arne Halberstadt: Deutsche Bundesbank, arne.halberstadt@bundesbank.de. Leo Krippner: Reserve Bank of New Zealand and Centre for Applied Macroeconomic Analysis, leo.krippner@rbnz.govt.nz.The authors thank Rafael Barros de Rezende, Iris Claus, Sandra Eickmeier, Sebastian Gehricke, Klemens Hauzenberger, Wolfgang Lemke, Emanuel Moench, Ken Nyholm, Esteban Prieto, Annukka Ristiniemi, Matthew Roberts-Sklar, Jelena Stapf, Borek Vasicek and participants of presentations at the Deutsche Bundesbank, the European Central Bank, the Reserve Bank of New Zealand, the CEF 2015 and the ICMAIF 2016 for helpful comments. The views expressed in this paper are the authors' personal opinions and do not necessarily reflect the views of the Deutsche Bundesbank or the Reserve Bank of New Zealand. 


\section{Introduction}

In this paper, we investigate the effect of the Effective Monetary Stimulus, which includes the influence of monetary policy conducted by conventional and unconventional means, on German and euro-area macroeconomic variables using a small-scale vector autoregression.

To begin the motivation for our investigation, short-maturity interest rates (hereafter, short rates) are often used to gauge the stimulus from conventional monetary policy (CMP) to the economy, given they are close to the policy rate set by central banks. However, in recent years, short rates have evolved to near-zero or mildly negative levels in many major economies, ${ }^{1}$ and so can no longer provide a complete indication of the overall stimulus. For example, figure 1 shows that the policy rate and the 3 -month rate in the euro area have remained close to zero since 2009, which would suggest relatively constant stimulus from the European Central Bank (ECB). ${ }^{2}$ However, the ECB has actually adopted a more accommodative policy stance than near-zero policy and short rates suggest, through unconventional monetary policy (UMP) actions. Those actions include long-term financing operations and asset purchasing programs, which are reflected in the ECB's balance sheet in figure 1. Additional actions are forward guidance, and announced but unimplemented policy programmes (e.g. Outright Monetary Transactions). These latter actions influenced monetary/financial conditions but not the ECB's balance sheet. A metric that consistently accounts for the overall stimulus from CMP, via a policy rate, plus the more recent range of different UMP actions would therefore be desirable.

For this reason we adopt and further develop, in ways to be detailed in section 2, the concept of the Effective Monetary Stimulus (EMS) from Krippner (2014). As an overview for the purposes of this introduction, our EMS at each point in time quantifies,

\footnotetext{
${ }^{1}$ The terminology "zero lower bound environment" is often used, reflecting that physical currency, with an interest rate of zero, is a substitute for electronic money balances should they offer negative rates. However, zero is not a hard limit; in principle, electronic money balances have a convenience value relative to physical currency and, in practice, the euro area itself is an example where mildly negative policy rates (down to -0.4 percent) have been implemented. But as noted in Bernanke (2017) p. 2, the option value of physical currency ultimately limits arbitrarily negative policy rate settings.

${ }^{2}$ For ease of exposition throughout the paper, we use "the ECB" to refer to the Eurosystem's joint conduct of monetary policy for the euro area.
} 
in a single summary value, the expected path of short rates plus term premiums, relative to the long-run nominal natural interest rate (i.e. the steady-state rate consistent with stable inflation and a zero output gap). Calculating this quantity over the entire sample period gives an EMS time series that indicates the overall stimulus to the economy across and within CMP and UMP environments. Importantly, while Krippner (2014) estimates the EMS from a shadow/lower-bound term structure model, our EMS turns out to be a simple combination of observable variables, with the primary component being longer-maturity interest rates. This result is appealing from two perspectives. First, our subsequent results obtained using the EMS are not subject to questions about generated regressors. Second, the EMS relates closely to the event-study literature that investigates the response of longer-maturity interest rates to UMP events, e.g. see Williams (2011) for an overview. As a related aside, the event study literature acknowledges the role of policy expectation and term premium channels in UMP transmission, e.g. see Woodford (2012), that our EMS intends to capture. However, because longer-maturity interest rates are subject to many influences, the EMS should not be interpreted as a direct substitute for a policy variable that the central bank tightly controls, like the policy rate or an asset purchase programme. Rather, the EMS is more akin to a component of monetary/financial conditions that the central bank can influence. Indeed, if markets are sufficiently familiar with the central bank's reaction function, through learning over history and/or central bank communication, then the EMS can even change in anticipation of likely central bank responses to evolving macroeconomic data. ${ }^{3}$

To test the EMS empirically, we use it initially within a standard vector autoregression (VAR), and then within the time-varying parameter VAR (TVP-VAR) of Primiceri (2005). Small-scale VAR models are often used to investigate the inter-relationships of monetary policy and macroeconomic variables, where the latter are typically those that reflect the ultimate targets of policy makers and/or key macroeconomic variables. In that regard, as detailed in section 3, our macroeconomic variables are inflation and an

\footnotetext{
${ }^{3}$ The points in the previous three sentences also apply to the shadow rate and "lift-off" estimates we discuss further below, because they are estimated from yield curve data.
} 
industrial production gap (as a monthly proxy for the output gap) for our applications to Germany and the euro area.

Our results, in sections 4 and 5, show that the EMS provides a more complete indicator of the stimulus to macroeconomic variables than the short rate (or shadow short rate estimates). Specifically, we find mainly plausible and reliable impulse responses to inflation and the output gap from our VAR and TVP-VAR using the EMS over both CMP and UMP periods in our sample, compared to mainly implausible responses with short rates (or shadow short rates which, for reasons discussed further below, we also tested). That is, the median responses of inflation and the output gap to EMS shocks mainly have the expected signs and profiles, although the responses in the UMP period are weaker and no longer statistically significant. The size of EMS shocks remains fairly constant across the sample, with larger persistence in the UMP period. We have also used alternative model specifications and data to establish the robustness of our results.

Having established stable relationships in our model, we then "take the EMS for a ride". Hence, in section 6, we provide a counterfactual analysis from the perspective of shocks to monetary/financial stimulus according to the EMS from the time of the Global Financial Crisis (GFC). We find that the EMS shocks have been stimulatory for most of the time since 2007 although, as discussed earlier, we cannot necessarily attribute that outcome specifically to ECB policy actions (unlike a typical policy rate counterfactual). For example, the EMS was at times subject to material tightening from events external to the ECB actions, resulting in inflation and the output gap falling below their counterfactual values. Nevertheless, the three clear periods where inflation and the output gap rise above their counterfactual values are preceded by the most stimulatory values of the EMS relative to its counterfactual, and those periods themselves coincide with major UMP events. Hence, while we are unable to quantify the explicit role of ECB UMP actions to economic outcomes in our present analysis, our small-scale VAR with the EMS appears to be useful for considering the stimulus to the economy across CMP and UMP environments. 
With respect to the related literature on investigating UMP effects on economic variables, the main difference of our investigation is our direct use of the information in long-maturity interest rates as the monetary/financial variable. Previous studies have used shadow short rate (SSR) series estimated from yield curve data, e.g. Francis, Jackson, and Owyang (2014), Wu and Xia (2016), and Mouabbi and Sahuc (2018). However, aside from being a generated regressor, SSR estimates are known to be sensitive to the shadow/lower-bound model specification and the data used for estimation. ${ }^{4} \mathrm{Wu}$ and Xia (2016) also used the "lift-off" horizon estimated from shadow/lower-bound models as a monetary/financial variable, but it is limited by the fact that a "lift-off" estimate is only available within lower-bound environments. The variables used in Lombardi and Zhu (2014) and Kucharcukova, Claeys, and Vasicek (2016) are essentially monetary conditions indices estimated from a range of variables including central bank balance sheet data. However, as mentioned earlier, central bank balance sheets do not reflect all UMP actions. Related, Weale and Wieladek (2016) use the announcements of large-scale asset purchases, which omits the effects of forward guidance and long-term financing operations.

The concept of our approach is closer to Gertler and Karadi (2015, GK), which considers the transmission of monetary policy in broader terms than the policy rate alone. ${ }^{5}$ GK does so by using a small-scale VAR with the financial variables being 1- or 2-year maturity interest rates and a measure that captures term premiums and credit costs, and consumer prices and industrial production as the macroeconomic variables. Quoting from GK p. 4647 "resulting 'modest' movements in short rates lead to 'large' movements in credit costs" and "a substantial impact on economic activity", and "forward guidance is important to the overall strength of policy transmission." The main differences in our approach are that we use expectations and term premium information in long-maturity interest rates, and

\footnotetext{
${ }^{4}$ For example, see Christensen and Rudebusch (2015), Krippner (2015a), and Bauer and Rudebusch (2016). Krippner (2017) shows how seemingly innocuous choices in the estimation of SSR series can make very material differences to the subsequent results obtained from macroeconomic models.

${ }^{5}$ We thank a referee for pointing out Evans and Marshall (1998) as a potentially related paper. However, while the VAR model in that paper includes macroeconomic variables, the paper's focus is investigating the effect of monetary policy shocks on the yield curve, rather than the effect of longer-maturity rates on the macroeconomy.
} 
we have not employed the GK high-frequency identification method to explicitly establish the response to exogenous monetary policy shocks. Hence, at this stage, our analysis establishes that the EMS provides a better measure of monetary/financial stimulus to the economy than the policy rate, but we have not identified the explicit/causal role of the central bank in delivering that stimulus. ${ }^{6}$

Finally, a notable difference to all of the literature referenced above is our use of TVPVAR, which allows for variation over time in the inter-relationships between the VAR variables and the size of innovations. The former flexibility allows for potentially different responses in the CMP and UMP environments, and the latter flexibility appropriately allows for the relatively stable economic and financial environment in the earlier part of our sample and the more variable years around the global financial crisis and the euro area debt crisis. We obtain similar results with a standard VAR, as we discuss in section 5, but find evidence for structural breaks that suggests the desirability of applying a TVP-VAR.

The outline for the remainder of the paper follows the section outlines already mentioned above, and section 7 concludes.

\section{The Effective Monetary Stimulus}

In this section we first provide an overview of the Effective Monetary Stimulus (EMS) concepts. Sections 2.2 and 2.3 then describe how we operationalize those concepts with appropriate proxy data to obtain the model-free EMS that we subsequently employ in our empirical application.

\subsection{Overview of the EMS}

Mechanically, as indicated in figure 2, the EMS we propose to use in this paper is the area between the lower-bounded nominal forward rate curve and the long-horizon nominal natural interest rate (LNIR), out to a given horizon (in this case 20 years). The EMS is

\footnotetext{
${ }^{6}$ In a related paper applying to the US, which is currently in progress, we identify the explicit role of the central bank using an identification method related to, but different than, that in GK.
} 
therefore the sum of two components: (1) the policy rate and its expected path relative to the LNIR; and (2) term premiums in interest rates. Note that the latter component is a distinct point of difference between our EMS and that proposed in Krippner (2014, 2015b), which only provides a gauge of the first component. Aside from term premiums being important to overall stimulus, as discussed shortly below, section 3.3 shows that including them allows our EMS to be obtained directly from observable data.

Regarding the expectations component, a policy rate setting below (above) the natural interest rate represents an accommodative (restrictive) stance of monetary policy. Expectations about the cumulative gap between the policy interest rate and the natural rate are also relevant for the degree of stimulus to the economy, given that it is an important consideration for the intertemporal consumption and investment decisions of economic agents. Textbooks, e.g. Walsh (2003), emphasize the role of policy expectations in principle and we thank a referee for pointing out that the New Keynsian framework also implies that the entire path of future policy rates matters for aggregate demand. Empirically, Gürkaynak, Sack, and Swanson (2005) is an example that establishes the importance of policy expectations, via a "future path of policy" factor. A related quote, in the context of the apparent market fixation on policy "lift-off" in the United States, also provides a colloquial reminder that the policy rate path matters more than any single rate on that path:

"For the purpose of meeting our goals, the entire path of interest rates matters more than the particular timing of the first increase" - Federal Reserve Vice Chairman Stanley Fischer, Jackson Hole, 29 August 2015.

Regarding the term premium component, this aspect has been emphasized as source of UMP stimulus via quantitative easing, targeted asset purchases and the portfolio balance effect; e.g. see Woodford (2012). However, term premiums will also influence effective monetary conditions in CMP environments. For example, even as the Federal Reserve raised the US policy rate in the mid-2000s, 10-year bond rates did not rise in tandem. 
That so-called "bond conundrum" was in part attributable to depressed term premiums (e.g. see the Adrian, Crump, Mills, and Moench (2014) estimates), which left 10-year bond yields and associated financing rates in the wider economy (e.g. mortgage rates) lower than might otherwise have been expected.

Panel 1 of figure 2 illustrates the concept of the EMS in a UMP environment, where forward rates and the yield curve data are constrained by the lower bound on nominal interest rates. In this case, the forward rate curve remains at near-zero levels until a future "lift-off horizon", from where it mean-reverts to the LNIR plus a long-horizon term premium (LRP). Note that the LRP is negative in this example, so the long-horizon forward rate is below the LNIR, but the LRP can adopt negative or positive values as it evolves over time. Panel 2 illustrates the concept of the EMS in a CMP environment, where forward rates and the yield curve data are unconstrained by the lower bound on nominal interest rates. In this case, the forward rate curve does not spend any time at near-zero levels and it freely mean-reverts to the LNIR plus the LRP.

The EMS can change over time with changes in the forward rate curve and/or the LNIR. The difference in forward rate curves is apparent between panels 1 and 2 and, regarding LNIR values, we have respectively used 5 and 5.5 percent in our illustrations. However, the variation of the LNIR over time should in principle be much less than for the forward rate curve, and that property is a feature of our observable proxy we use for the LNIR, as discussed in the following section. The forward rate curve changes more quickly and by greater amounts, reflecting changes to the expected path of the policy rate and/or term premiums underlying the yield curve data.

The EMS in panel 1 is larger than the EMS in panel 2, and so represents a larger stimulus to the economy. However, because the EMS is not under the strict and direct control of the central bank, like a policy rate or balance sheet actions, it would not be strictly correct to denote the larger EMS value as a more accommodative stance of monetary policy. Rather, the EMS is influenced by any factors that impact on longermaturity interest rates, and so it should be treated as a market expectation variable 
subject to central bank influence, like an element of monetary/financial conditions. Some of those factors may be independent of the central bank, such as investor's reactions to market uncertainty and/or spillovers from foreign financial markets, and some factors will be attributable to the central bank. Also, if markets are sufficiently familiar with the central bank's reaction function (e.g. through learning over history and/or central bank communication), then the EMS can change in anticipation of likely future central bank responses to currently evolving macroeconomic data. For the reasons in this paragraph, we refer to the EMS as a measure of "monetary/financial stimulus" throughout this paper, as distinct from a monetary policy variable and/or actions that can be tightly controlled by the central bank.

\subsection{Proxy for the LNIR}

We proxy the LNIR at each point in time, which we denote $\operatorname{LNIR}(t)$, using an observable variable from Consensus Forecast surveys. Specifically, we use the 6-10 year horizon survey results for real output growth and inflation, as available at the time, and we combine those into expected nominal output growth. Figure 3 plots the result. The values are only available biannually (in April and October) until 2014, and quarterly afterwards. We obtain a monthly series by simply holding the previous values until the next value is available. Also note that, despite the survey result being for the 6-10 year horizon, we are treating them as asymptotic values. The justification is that if an appropriate parametric model were applied to the survey expectations data, e.g. in the manner of Aruoba (2016), the asymptotic value of that model would be dominated by, and hence very close to, the longest-horizon survey data. ${ }^{7}$

The justification in principle for using long-horizon nominal output growth as a proxy for the $\operatorname{LNIR}(t)$ is the standard result from the Solow-Swan model and the Ramsey neoclassical models; e.g. see Barro and Sala-i-Martin (2004). Specifically, in the steady

\footnotetext{
${ }^{7}$ Aruoba (2016) uses the Nelson and Siegel (1987) specification. In that specification, the asymptotic value is the estimated Level component, and its value is close to the survey data for the longest horizon.
} 
state of those models, the real interest rate is within a constant of real output growth. ${ }^{8}$ Adding a steady state inflation rate then produces the analogous nominal relationship. The Consensus Forecast long-horizon surveys provide an average of analyst long-horizon expectations of real output growth and inflation, and therefore represent an observable variable to proxy long-run/equilibrium nominal short-maturity interest rate that we require for the EMS. We are aware of Consensus Forecast long-horizon surveys being used in this manner by the Bank of England and the ECB.

As mentioned in the previous section, changes to the LNIR are one source of changes to the EMS, because it changes the gap between the expected policy path and the LNIR. This can be quite material over the passage of time. For example, figure 3 shows that the LNIR falls from 4.3 percent in 1998 to 3.3 percent in 2015. Presumably, changes in $\operatorname{LNIR}(t)$ will in turn reflect analyst views on long-horizon potential output growth (in turn potentially due to changes in population growth, productivity growth, etc.) and/or long-horizon inflation expectations (in turn potentially due to perceptions about central bank inflation targets, policy credibility, etc.). However, we simply use the series as data and make no assumptions about their underlying drivers.

As an important point of clarification, aside from being a nominal value, our LNIR differs deliberately in two respects from the real natural interest rates of Laubach and Williams (2015) and Holston, Laubach, and Williams (2017, HLW). First, to quote from the abstract of HLW, the concept of the such estimates are "the real short-term interest rate that would prevail absent transitory disturbances", whereas we require a longer-run value to provide a like-with-like comparison with forward rates over longer horizons. ${ }^{9}$

\footnotetext{
${ }^{8}$ The Ramsey-Kass-Koopmans steady state result is often expressed as the interest rate being within a constant of output growth per capita. To reconcile that expression with our statement in the text, note that the subjective discount rate $\mathrm{r}_{\delta}$ in the consumption Euler equation must at least equal population growth $n$ in order to satisfy the transversality condition. Hence, $\mathrm{r}_{\delta}$ may be rewritten as $\mathrm{r}_{\delta}=n+\Delta \mathrm{r}_{\delta}$, where $\Delta \mathrm{r}_{\delta}$ is some positive increment. The population growth inherent in $\mathrm{r}_{\delta}$ therefore nets out with steady state per capita consumption growth, hence giving our stated version of the relationship.

${ }^{9}$ For this reason alone, one would expect the real component of our LNIR to often differ from the Laubach and Williams (2015) and Holston, Laubach, and Williams (2017) real natural interest rates. For example, the updated Laubach and Williams (2015) estimate for 2018Q1 in the United States is 0.14 percent. The longer-run FOMC projections for the 21 March 2018 meeting have a range of 2.3-3.5 percent which, using the 2 percent PCE inflation projection, implies a $0.3-1.5$ percent longer-horizon real rate (similar in concept to the LNIR).
} 
Second, the Laubach and Williams (2015) and HLW natural rates are estimated (from a small-scale model incorporating inflation, the output gap, and trend output growth rates), and so are generated regressors that will be subject to model and estimation uncertainties. We choose to use an observable proxy for LNIR so we do not have to allow for such uncertainties. ${ }^{10}$

\section{$2.3 \quad$ Model-free EMS}

Section 2.1 introduced the EMS as a quantity based on the area between the lowerbounded forward rate and the LNIR up to a given horizon $\tau_{\mathrm{H}}$. The mathematical expression for that area is an integral, ${ }^{11}$ and, for reasons we will discuss shortly below, we scale that by $\tau_{\mathrm{H}}$ to obtain our EMS, i.e.:

$$
\operatorname{EMS}\left(t, \tau_{\mathrm{H}}\right)=\frac{1}{\tau_{\mathrm{H}}} \int_{0}^{\tau_{\mathrm{H}}}[\underline{\mathrm{f}}(t, \tau)-\operatorname{LNIR}(t)] \mathrm{d} \tau
$$

where $\operatorname{EMS}\left(t, \tau_{\mathrm{H}}\right)$ is the EMS at time $t$ for a given horizon $\tau_{\mathrm{H}}, \underline{\mathrm{f}}(t, \tau)$ is the lower-bounded forward rate at time $t$ as a function of horizon $\tau$, and $\operatorname{LNIR}(t)$ is the $\operatorname{LNIR}$ at time $t$, but which has no dependence on the horizon $\tau$. Note that the EMS is a signed quantity; $\underline{\mathrm{f}}(t, \tau)$ below the $\operatorname{LNIR}(t)$, as in figure 2, would produce a negative value (i.e. accommodative monetary/financial conditions), and $\underline{\mathrm{f}}(t, \tau)$ above the LNIR would produce a positive value (i.e. restrictive monetary/financial conditions). An EMS value could also potentially be the net of positive components for some horizons and negative components for other horizons, which would arise from $\underline{\mathrm{f}}(t, \tau)$ rising or falling through the $\operatorname{LNIR}(t)$ value for some horizons.

\footnotetext{
${ }^{10}$ Nevertheless, we realize that surveys are by no means perfect. For example, one unavoidable issue is that they only represent the views of a small (but arguably well-informed) subset of financial market participants and the general population. Hence, surveys can only ever provide an approximation to the actual expectations held within financial markets and the macroeconomy.

${ }^{11}$ Some readers may be more familiar with discrete-time term stucture notation rather than our continuous-time notation, in which case the forward rate would be expressed as $\underline{\mathrm{f}}(t, i, i+1)$, where $i$ is an integer representing multiples of discrete time steps $\Delta t$. The integral would then be the summation $\sum_{i=0}^{I-1}[\underline{\mathrm{f}}(t, i, i+1)-\operatorname{LNIR}(t)] \Delta t$, and interest rates would be $\underline{\mathrm{R}}(t, I)=\frac{1}{I} \sum_{i=0}^{I-1} \underline{\mathrm{f}}(t, i, i+1)$, where $I$ is the number of time steps to maturity. Note that all rates are continuously compounding, whether using continuous- or discrete-time notation, which is why integrals or summations are appropriate.
} 
Equation 1 can be simplified by separating the $\underline{\mathrm{f}}(t, \tau)$ and $\operatorname{LNIR}(t)$ terms, i.e.:

$$
\begin{aligned}
\operatorname{EMS}\left(t, \tau_{\mathrm{H}}\right) & =\frac{1}{\tau_{\mathrm{H}}} \int_{0}^{\tau_{\mathrm{H}}} \underline{\mathrm{f}}(t, \tau) \mathrm{d} \tau-\frac{1}{\tau_{\mathrm{H}}} \int_{0}^{\tau_{\mathrm{H}}} \operatorname{LNIR}(t) \mathrm{d} \tau \\
& =\underline{\mathrm{R}}\left(t, \tau_{\mathrm{H}}\right)-\operatorname{LNIR}(t)
\end{aligned}
$$

where the lower-bounded interest rate $\underline{\mathrm{R}}\left(t, \tau_{\mathrm{H}}\right)$ arises from the standard definition that connects interest rates and forward rates (in this case, both subject to the lower bound); e.g. see Filipović (2009) p.7. Expressing the EMS directly in terms of interest rates is one reason why scaling by $\tau_{\mathrm{H}}$ is convenient. Two other reasons are: (1) it allows $\operatorname{EMS}\left(t, \tau_{\mathrm{H}}\right)$ to be viewed intuitively as the average difference between $\underline{\mathrm{f}}(t, \tau)$ and $\operatorname{LNIR}(t)$ out to the horizon $\tau_{\mathrm{H}}$; and (2) it obtains EMS values of similar magnitudes for different horizons, because the EMSs are effectively annualized, which better allows for comparing EMS calculations for different horizons. Of course, for a given horizon $\tau_{\mathrm{H}}$ the unscaled quantity $\tau_{\mathrm{H}} \cdot \operatorname{EMS}\left(t, \tau_{\mathrm{H}}\right)$ would have precisely the same statistical properties as $\operatorname{EMS}\left(t, \tau_{\mathrm{H}}\right)$, so scaling by $\tau_{\mathrm{H}}$ is inconsequential for our subsequent empirical analysis.

Importantly, $\underline{\mathrm{R}}\left(t, \tau_{\mathrm{H}}\right)$ is an observed variable; it is simply the $\tau_{\mathrm{H}}$-maturity interest rate. $\underline{\mathrm{R}}\left(t, \tau_{\mathrm{H}}\right)$ will be subject to the lower bound constraint that the market perceives to apply at time $t$, but there is no need to assume or estimate the lower bound (whereas measures from a shadow/lower-bound term structure model would require a lower-bound specification and the estimation of the model from the data). Using an observed interest rate $\underline{\mathrm{R}}\left(t, \tau_{\mathrm{H}}\right)$ is particularly appealing because, in conjunction with our observable $\operatorname{LNIR}(t)$ proxy discussed in the previous section, it enables us to obtain fully observable EMS data rather than using EMS estimates that would be generated regressors subject to model and estimation uncertainties.

Note that, if $\operatorname{LNIR}(t)$ were constant, say $\overline{\operatorname{LNIR}}$, then the EMS would be statistically identical to the $\tau_{\mathrm{H}}$-maturity interest rate, i.e.:

$$
\overline{\operatorname{EMS}}\left(t, \tau_{\mathrm{H}}\right)=\underline{\mathrm{R}}\left(t, \tau_{\mathrm{H}}\right)-\overline{\mathrm{LNIR}}
$$


In this case, we can simply use the $\tau_{\mathrm{H}}$-maturity interest rate as a direct proxy for the EMS. In principle, we believe that allowing for a time-varying LNIR should be important, because the stimulus from interest rates at a given point in time should depend on their level relative to the neutral level at a given point in time, and both our proxy and the other references from the previous section suggest that the LNIR has varied materially over time. For example, the 1 percentage point fall (from 4.3 to 3.3 percent) in the LNIR mentioned in the previous section, in 2015 indicates that nominal interest rates would need to be 1 percentage point lower, on average, to provide the same amount of monetary/financial stimulus as in the past. We discuss the related empirical results in our robustness section 5.4 .

Regarding the maturity $\tau_{\mathrm{H}}$, we choose 30 years, and figure 3 therefore plots the 30 -year EMS. Our choice of 30 years is a compromise between practical and theoretical considerations. From a practical perspective, 30 years is the longest-maturity benchmark interest rate quoted in major markets and is therefore least subject to the attenuation in movement, and hence potential loss of information, that occurs with the interest rates of other maturities as they approach the lower bound (see, e.g., Kim and Singleton (2012) and Christensen and Rudebusch (2015) for discussion and estimation of such attenuation). From a theoretical perspective, the longest-maturity interest rate is closest to the infinite horizon for consumption utility maximization that underlies many standard macroeconomic models. In addition, longer-maturity interest rates are likely to better reflect the term premiums that QE actions are thought to influence via portfolio rebalancing effects; e.g. see Woodford (2012). A longer-maturity interest rate will at the same time account for the whole path of expected policy rates, which includes the shorter horizons over which the central exerts most control via the policy rate and forward guidance, but also the expectations extending over typical business cycle lengths. Our results imply that using longer-maturity data is important empirically; as we discuss in the robustness section 5.4, we obtain similar results with EMS series obtained with 7- and 10-year interest rate data, but not with the 3-year rate. 


\section{Data}

We use a German dataset, as illustrated in figure 4, and a euro area dataset for our analysis. Both are monthly to allow for the largest number of observations, and start from 1993 to avoid the one-off German reunification event in 1990. The last observation is December 2017, which is the last observation available at the time we began the analysis.

Our German dataset provides the longest time series of self-consistent macroeconomic and EMS data, by which we mean that a unique currency (i.e. the Deutsche Mark, and then the euro from January 1999) and monetary policy applied at all times. It also allows for a larger range of alternative macroeconomic indicators for the robustness checks that we report in section 5.4. Hence, we use our German dataset to obtain our benchmark results reported in sections 4 and 5. For the euro area, we create an analogous dataset using artificial/constructed macroeconomic data prior to 1999, even though this is not strictly self-consistent given the absence of a single currency or monetary authority prior to January 1999. However, as discussed in section 5.4, we nevertheless obtain results closely consistent with those from our German dataset.

For our measure of price inflation, we use a producer price index (PPI). For Germany, we use the index for commercial goods sold inland from the German Federal Statistical Office, which is an ex-energy measure. For the euro area, we use the inland PPI ex-energy from Eurostat, and we transform both PPI levels into annual rates of inflation. These PPI inflation rates have the advantage of avoiding temporary influences from energy prices and changes in the exchange rate that the ECB would most likely "look through" when forecasting and targeting inflation over the medium-term (as per the 2003 clarification of the 1998 inflation target based on HICP inflation). They also control, at least in part, for exchange rate effects on prices without having to introduce another variable. ${ }^{12}$

\footnotetext{
${ }^{12}$ The effects of a monetary policy shock on exchange rates have been found to be puzzling in some vector autoregression analyses, particularly in the case of Germany, e.g. see Sims (1992) and Grilli and Roubini (1996). Related, movements in the exchange rate can also support the incidence of a price puzzle, i.e. a positive response of the price index to a contractionary monetary policy shock. Elbourne and de Haan (2009) is an example that includes the exchange rate as a separate variable, and Kucharcukova et al. (2016) include the exchange rate as a component in the monetary conditions index. We prefer to
} 
For our measure of economic activity, we use industrial production to provide a monthly proxy for the output gap and also to match our use of the PPI as the inflation measure. Such a proxy is also used elsewhere in the literature; e.g. see Clarida, Gali, and Gertler (1998) for the United States, and Kucharcukova et al. (2016) for the euro area. ${ }^{13}$ Specifically, we calculate an industrial production gap (IP-G) as the log-level deviation of seasonally adjusted industrial production, from the German Federal Statistical Office and Eurostat for the German and euro-area datasets respectively, from the time-varying trend obtained with the Hodrick-Prescott filter; e.g. see Engel and West (2006) and Taylor and Davradakis (2006). As suggested by Ravn and Uhlig (2001), we apply a smoothing parameter of 129,600 for a series of monthly observations.

In both the German and euro area datasets, we include a commodity price index (CPM), which has a long precedent in the related literature; e.g. see Sims (1992) and Christiano, Eichenbaum, and Evans (1996). As those authors point out, including commodity prices helps to alleviate the price puzzle, because it takes into account anticipated inflationary pressure that is not yet reflected in the other variables of a small-scale VAR. We use the World Bank commodity price index for metals and minerals from their website, transformed into an annual rate of inflation. ${ }^{14}$

Our EMS requires an LNIR series and a series of 30-year interest rates, and we construct both as piecewise series due to data availability. For the LNIR series, we use German Consensus Forecast data up to December 1998, an equal-weighted combination of German and French Consensus Forecast data from January 1999 to March 2003, and then euro area Consensus Forecast data when it first became available in April 2003. For the 30-year interest rate series, we use German 30-year government bond interest rates

retain parsimony, given our aim to test the EMS as a monetary/financial conditions metric, but adding the exchange rate would be a useful extension in future work.

${ }^{13}$ German and euro area industrial production respectively had a 25.8 and 20.1 percent share of German and euro-area GDP in 2016.

${ }^{14}$ See pubdocs.worldbank.org/en/561011486076393416/CMO-Historical-Data-Monthly.xlsx. In earlier analysis, we used IMF commodity price indices for metals or for agricultural goods, and both led to very similar results. At the time of updating our analysis, however, we found that updates to the IMF indices had been suspended. The World Bank metals and minerals index is highly correlated $(>0.97)$ with the IMF metal index. 
up to December 1998, an equal-weighted combination of 30-year German and French government bond interest rates from January 1999 to May 2008, and then 30-year overnight indexed swap (OIS) data from June 2008, when reliable 30-year rates first became available. The OIS data is most preferable because they are interest rates that are directly relevant to the whole euro area. However, the combination of the German and French data provides a close proxy in the earlier periods. Importantly, our use of OIS begins prior to the Global Financial Crisis and European sovereign crisis. During those periods, German bonds in particular were influenced by safe-haven/risk-aversion factors, and so using those yields after the Global Financial Crisis would not provide a proxy for monetary policy expectations and term premiums relevant to the whole of the euro area.

Finally, to best motivate our EMS as measure of stimulus, we compare our EMS VAR results to VARs using more standard stimulus measures. Hence, we also construct a 3month interest rate series as for our 30-year rate series, and we estimate an SSR series from a yield curve dataset constructed as for our 30-year rate series. Figure 5 plots the three variables we have tested as measures of monetary/financial stimulus. Note that our EMS and short rate variables are the same for both the German and euro-area datasets. Implicitly, and we think reasonably, German monetary policy is therefore imposed as the de facto setting for the euro-area dataset prior to January 1999.

For all of our VAR estimations, we have identified the monetary/financial stimulus shocks as standard in the literature, i.e. using a recursive ordering with the macroeconomic variables ahead of the monetary/financial stimulus variable. The macroeconomic variables can therefore only react with a lag to monetary/financial stimulus shocks, while a shock to the macroeconomic variables can affect the monetary/financial stimulus variable contemporaneously. ${ }^{15}$

\footnotetext{
${ }^{15}$ We order CPM inflation directly after PPI inflation, because the former is used as a proxy for anticipated inflation, but reversing the order of CPM inflation (a fast-moving variable) and the industrial production gap (a slow-moving variable) does not materially change the results presented in sections 4 and 5 .
} 


\section{Standard VAR estimation and results}

As an initial investigation, we estimate a standard VAR with a four-lag specification. ${ }^{16}$ We estimate the VAR over the full sample period, and separately for the CMP and UMP periods. The estimation over the CMP sub-sample is an important element of our comparison, because it allows a "like-for-like" comparison between the EMS and the short rate when both were freely varying. To be clear, for the reasons outlined in section 2, we expect the EMS to provide a more comprehensive indication of overall stimulus to the economy than the short rate, but a comparison in the CMP environment is required to test that. Related, Gertler and Karadi (2015) also report results from just the CMP period to show that their VAR model with credit variables performs better than a standard set-up with just short-maturity rates.

Our subsequent estimation over the full sample then allows us to assess how the EMS has performed as a measure of stimulus across the CMP and UMP periods, which is itself a precursor to gauging how UMP may have influenced the economy in the wake of the GFC. The UMP sub-sample is required for the structural break tests we report below, so we have included those results for completeness.

Figure 6 contains the impulse response functions (IRFs) when using the EMS as the monetary/financial variable. The IRFs are in the units of the original series, and the confidence intervals on all figures are the 16th and 84th percentiles, as in Primiceri (2005), which we will use as the threshold for statistical significance in our discussions. Figure 7 contains the IRFs when using the 3-month rate.

The essential points from figures 6 and 7 are that using the EMS as the monetary/financial stimulus variable in the VAR obtains generally plausible IRFs for the macroeconomic variables; i.e. PPI inflation and the IP-G decline over medium horizons following a tightening monetary/financial shock according to the EMS. However, there is an initial positive response for the IP-G in the UMP period, and that also shows up for

\footnotetext{
${ }^{16}$ The Akaike information criterion suggested four lags. The Schwartz Bayesian information criterion suggested a single lag, but the standard errors impulse response functions from that specification were all insignificant.
} 
the full sample. Conversely, when using the 3-month rate, the IRFs for the macroeconomic variables are initially all counterintuitive for horizons out to about one year, i.e. economically material and statistically significant positive responses of both inflation and the output gap to a tightening shock. Hence, even though we have used commodity prices as a standard control, we still get a price puzzle. Also, the median response of the IP-G in the CMP period never becomes negative Using our representative SSR series as the monetary/financial stimulus variable obtains results intermediate to those with the EMS and the 3 -month rate; see figure 16 in appendix B. The notable shortcoming is again the lack of a median negative response for the IP-G in the CMP period, as for the 3-month rate results. Of course, the SSR results are dependent on the particular series we have used, and a complete assessment would need to account for the model and estimation uncertainties inherent with SSR estimates.

Table 1 reports the Candelon and Lütkepohl (2001) tests for a structural break between the CMP and UMP period. The results are very strongly significant, i.e. well beyond the 1 percent level, for all of the standard VAR models. Hence, none of the monetary/financial stimulus variables we have tested maintain a time-invariant linear relationship with our macroeconomic variables over the CMP and UMP periods of our sample. However, the structural break tests arguably favour the EMS relative to the 3-month rate (or the SSR) for standard VAR analysis covering CMP and UMP periods. That is, the smaller test statistics for the EMS suggest less evidence against a time-invariant linear relationship when using it as a monetary/financial variable in conjunction with the other variables, compared to using the 3-month rate (or the SSR).

Nevertheless, given the evidence that none of the EMS maintain the dynamic properties of the VAR between the two periods, allowing for time variation is more appropriate. We do so in the following section with the TVP-VAR of Primiceri (2005). 


\section{TVP-VAR estimation and results}

In this section we present the results obtained from the TVP-VAR of Primiceri (2005), which we have estimated with the four lags suggested for the standard VAR in section 4. The full details on the TVP-VAR specification are contained in appendix A. When estimating the TVP-VAR, we use the data from April 1993 to December 1998 as the training sample. Our actual estimation sample starts in January 1999, to coincide with the introduction of the EMU. For each estimation, we draw 30,000 times from the Gibbs sampler, and the first 20,000 draws are removed as burn-in.

\subsection{Time variation in the TVP-VAR}

Figure 8 contains plots of the forecast error variances (which we hereafter abbreviate to "volatility") for the variables in the TVP-VAR estimated with the short rate (shown as black lines) or the EMS (shown as blue-dashed lines) as the monetary/financial stimulus variable. In both cases, the macroeconomic data and commodity prices show heightened volatility around the time of the GFC, with a gradual return to around pre-GFC levels. The time variation in volatility is likely one source of the structural break results reported in section 4.

Regarding the monetary/financial stimulus variables, the volatility of the short rate (top-left panel) spikes at the beginning of the 2000s, at the high points of the GFC in 2007, and during the sovereign debt crisis in 2011. It has remained close to zero in recent years, reflecting constrained movements within lower bound environment. The short rate model therefore suggests that stimulus to the economy has not varied much in recent years, which partly reflects that the short rate does not capture the additional UMP actions undertaken by the ECB.

Conversely, the volatility of the EMS remains relatively stable over the entire sample (top-right panel). The EMS model therefore suggests that stimulus to the economy continues to vary even in the UMP period, which is more consistent with the additional 
UMP actions undertaken by the ECB that have influenced policy rate expectations and term premiums to provide additional stimulus.

The other parameters of the VAR also vary over time, although less materially than the volatility. Indeed, we find little variation in the coefficient matrices, but more in the intercept terms and the matrix that allows shocks to one variable to be transmitted to other variables. The parameters in the TVP-VAR we use can therefore adjust smoothly to structural changes which would cause a structural break in a less flexible VAR setup; see also Baumeister and Peersman (2013). We have relegated the figures showing the evolution of the TVP-VAR parameters over time to appendix B. In sections 5.2 and 5.3 we focus on the impulse response functions (IRFs) from the TVP-VAR. To indicate the variation in the IRFs, we have simply plotted three results to represent the results over each period in the given sample. We believe that shows greater clarity relative to threedimensional plots and it saves space, but we are happy to provide the IRF results for any or all periods on request.

\subsection{CMP sub-sample impulse responses}

Figures 9 and 10 contain the IRFs (in units of standard deviation, also for figures 11 and 12) to shocks in the short rate and the EMS, respectively, for the TVP-VAR estimated only up to the end of the CMP period. For the short-rate TVP-VAR, the profiles of the inflation IRFs are similar to those for the standard VAR, with positive initial responses followed by negative medium-horizon responses. However, the IRFs for the IP gap differ from the standard VAR results in not having the decline for medium horizons, while the counterintuitive initial positive response remains. The magnitudes of the IRFs reflect that the size of the short rate shock is higher in the earlier part of the CMP period than in later years.

For the EMS TVP-VAR, the profiles of both the inflation and IP gap IRFs are more plausible than in figure 7. Furthermore, the magnitudes of the IRFs also broadly coincide 
for all periods, which reflects that the sizes of EMS shocks are almost constant over time. ${ }^{17}$

Overall, the EMS appears to be more suitable than the short rate as a measure of stimulus in the CMP period, even though both could vary freely. That confirms our expectation, and results from section 4, that the EMS provides a more comprehensive indication of the overall stimulus to the economy even prior to the UMP period.

\subsection{Full sample impulse responses}

Figures 11 and 12 contain the IRFs to shocks in the short rate and the EMS, respectively, for the TVP-VAR estimated for the full sample.

The IRFs for the macroeconomic variables in the short-rate TVP-VAR turn out to be similar to those already discussed for the CMP period. Notably, the IRFs for the IP gap remain counterintuitively positive or insignificant at all horizons. The magnitudes of the IRFs reflect the pattern of volatility for the short rate from figure 8, which was elevated in for the mid-sample (January 2008) result we have plotted.

The EMS TVP-VAR continues to provide more plausible results, being similar to those already discussed for the CMP period. However, there are three notable differences: (1) the IP gap IRF is positive for very short horizons (which also occurred in the standard VAR); (2) near the end of the sample (January 2016), the declines in the inflation and IP gap responses for medium horizons are no longer significant (although they are negative, and the price puzzle from the 3-month VAR is avoided); and (3) the own-response of the EMS to an EMS shock is more persistent near the end of the sample (see the bottom-right sub-plot of figure 10).

The lower significance for responses to inflation and economic activity in recent years is consistent with Wu and Xia (2016), for the United States, and Kucharcukova et al. (2016) for the euro area. This may represent changes to the transmission of monetary/financial

\footnotetext{
${ }^{17}$ The responses of commodity inflation are similar to the PPI inflation responses, in magnitude, profile, and significance. Of course, as discussed in Sims (1992) and Christiano et al. (1996), the commodity price index is only present to control for expected price developments and the results should not be taken to imply that a monetary policy shock in one economy is a material driver of any global commodity price index.
} 
stimulus in the environment of extraordinary low interest rates, which supports the case for applying a TVP-VAR to account for such changes, or it may be due to aspects that are outside the dimension of our VAR (e.g. uncertainty).

The change in the persistence of EMS shocks is consistent with the change in both the instruments and intentions of monetary policy between the CMP and UMP periods. That is, in the first part of our sample, EMS shocks were delivered via surprises in the policy rate and/or expectations of policy rate settings, and agents could reasonably expect those adjustments to be temporary with respect to the economic cycle. Conversely, in the second part of our sample, EMS shocks were delivered via quantitative policy actions and long-horizon forward guidance, which the ECB has explicitly communicated are intended to last for an extended period of time.

The size of the impulse responses of the macroeconomic variables to a shock on the EMS is mostly higher than when using the short rate as a monetary/financial stimulus variable. Because the shock size is one standard deviation in both cases, the different responses are due to the informational content of the monetary/financial stimulus variable. Hence, the larger impulse responses using the EMS reflects additional information about the stimulus to the economy compared to the policy rate, particularly in the UMP period.

\subsection{Robustness checks}

We have undertaken a wide range of robustness checks for the results reported in sections 5.2 and 5.3. ${ }^{18}$ For our application to Germany, these include using alternative inflation data (headline annual inflation using harmonized index of consumer prices, HICP), alternative control variables for expected inflation (agricultural commodity price inflation, surveyed inflation expectations, and no control variable), alternative economic activity data (unemployment, and a macroeconomic factor estimated as the first principal component of 74 macroeconomic series), and alternative EMS data (calculated with 3-, 7-,

\footnotetext{
${ }^{18}$ We have exluded the related figures for brevity, but we are happy to share any or all of our results on request.
} 
and 10-year interest rates, and simply using the 30-year rate itself). The broad results are that the checks do not overturn the results we have discussed in detail for the German dataset, but there is one exception and another result worthy of further comment.

The exception is when we use the 3-year rate to calculate the EMS. This results in an EMS series with materially different statistical properties to the 7-, 10-, and 30-year EMS series, and the 3-year EMS TVP-VAR has correspondingly less plausible impulse responses. Hence, so long as the EMS uses an interest rate that extends beyond the typical business cycle, the choice of $\tau_{\mathrm{H}}$ is not critical for our subsequent empirical analysis. Conversely, a $\tau_{\mathrm{H}}$ value that is less than the typical business cycle should not be used because it would omit information relevant to the expected policy rate over the full business cycle.

The other point of note is that we find the IRF results from using the 30-year EMS with a time-varying LNIR are slightly better, i.e. more plausible and significant, than those with just the 30-year interest rate alone. As discussed in section 2.3, the latter is equivalent to an EMS calculated with a constant LNIR. Hence, there is a mild empirical benefit to assessing the monetary/financial stimulus from interest rates relative to a timevarying neutral benchmark. That result is consistent with the principle that time-variation in both interest rates and their neutral benchmark should ideally be accounted for when assessing net monetary/financial stimulus.

As a robustness check on the results for the UMP period, we have repeated the exercise with an estimation from 2008 to 2017 using all the results prior to then as the training sample. The results show median estimates of the impulse responses that are very similar to those discussed above. Predictably, however, the smaller sample period delivers wider confidence intervals for the impulse responses, so many of the IRFs are no longer significant.

We have also re-estimated our TVP-VAR model using the euro area dataset described in section 3. With the EMS as monetary/financial stimulus variable, the inflation responses are just slightly less significant than in the case of German data. Also the impulse 
responses of the IP gap are similar to those for the German dataset, but they are insignificant at each point in time, rather than being significant for medium term horizons. When estimating the VAR with the short rate as monetary/financial stimulus variable, we also find the same counterintuitive response of the IP gap as for the German dataset.

Finally, to test the potential for different effects of the EMS between the core and peripheral euro area economies, we have also estimated TVP-VAR models for Italy, Spain, and France. The availability of data for those individual countries constrains us to use HICP inflation and the IP gap in all cases, which we also obtain for the euro area for comparison. The IRFs for France are similar to those from Germany and the euro area. The IRFs of Italy and Spain differ from the results for France, Germany, and the euro area, but the divergences are rather small and are not identical for those two peripheral economies. In other words, we do not find effects from EMS shocks that are systematically unique to core or periphery economies, or to individual economies. These results reinforce the notion that the EMS provides a broad measure of monetary/financial stimulus to the macroeconomy, i.e. the euro area in our application. ${ }^{19}$

In general, the results discussed above provide assurance that the detailed results we have reported earlier in are generally applicable to the consideration of monetary/financial stimulus for individual euro countries and across the euro area. And, as previously discussed, the EMS appears to provide a useful measure of monetary/financial stimulus over CMP and UMP periods, so our benchmark model should be applicable to considering the effects of that stimulus over both periods.

\section{Counterfactual analysis}

In this section we "take the EMS for a ride" by providing two examples of counterfactual analysis from the perspective of monetary/financial shocks according to the EMS, in the

\footnotetext{
${ }^{19}$ As a related point, if one was particularly interested in further explaining the unique/idiosyncratic outcomes for a given economy or subset of economies, our results would suggest using economy-specific variables (e.g. sovereign bond spreads, credit conditions, banking statistics, etc.) in conjunction with the EMS. See, for example, von Borstel, Eickmeier, and Krippner (2016).
} 
lead-up and wake of the GFC. In the first counterfactual exercise we zero out our estimated EMS shocks from the TVP-VAR. Our second exercise, which as we discuss further below is more subject to the Lucas critique, maintains the EMS at its neutral level.

Regarding the first exercise, figure 13 plots the realized EMS and the counterfactual EMS with our estimated shocks excluded (the figure uses natural units, i.e. percentage points, for easier interpretation). ${ }^{20}$ The first point of note from figure 13 is that the counterfactual itself trends down, by around 2 percentage points, over the UMP period. That trend indicates that a material share of the EMS decline over the UMP period was a response (from the deterministic part of the TVP-VAR) to low outcomes of inflation and the output gap, rather than due to EMS shocks (from the TVP-VAR residual matrix). Shocks to the EMS mostly added to monetary/financial stimulus over the UMP period, by up to around 0.8 percentage points, which is apparent from the realized EMS being below its counterfactual over most of the UMP period.

To gauge the estimated influence of the shocks to monetary/financial stimulus according to the EMS on the macroeconomy, figure 14 plots the deviations in the EMS and the other variables in the TVP-VAR from their counterfactual values, again all in their natural units for more ready interpretation. These counterfactuals for inflation and the output gap (as proxied by our PPI and IP-G variables) may seem underwhelming if interpreted from the perspective of what was a series of unprecedented policy easing actions put in place by the ECB following the GFC. However, the results in figure 14 cannot, and should not, be interpreted as estimated causal effects of ECB policies on the EMS, and the associated outcomes of inflation and output gap, relative to those policies not being enacted. One reason, as mentioned earlier, is that those policy easing actions were largely anticipated by markets, so the shocks alone are unlikely to represent the full extent of the ECB's influence. A second reason is that, while the EMS shocks include the influence of unanticipated ECB policy actions (and/or their timing) on longer-maturity interest rates,

\footnotetext{
${ }^{20}$ Counterfactual results from TVP-VARs in the literature are often insignificant and the confidence intervals in figure 13 show that, for most of the time, our results are no exception. We therefore focus on the point estimates for the remainder of this section.
} 
the EMS also includes other influences on longer-maturity interest rates that may be independent of ECB actions and intentions. Hence, unlike counterfactual analysis based on a policy rate or short rate over which the central bank exerts tight control, the realized EMS versus its counterfactual will not all be due to central bank policy actions.

To specifically gauge the effect of ECB policy on the macroeconomy, we would ideally like to decompose the EMS and its shocks into estimates associated with ECB policy and non-ECB components. However, the framework we have used in this paper does not allow a precise quantitative decomposition and attribution to ECB policy. Nevertheless, by highlighting the periods where ECB and non-ECB influences were most likely at play, we can use our counterfactual results to provide an approximate gauge of the influence from ECB policy in the UMP period.

Regarding non-ECB components, there are three notable periods following the GFC when the EMS rose and even became contractionary relative to its counterfactual. Those periods predominantly coincided with episodes of rising US bond rates, and its associated spillover to longer-maturity rates in other economies, rather than an intention of the ECB to actively adopt a less expansionary stance of monetary policy. The first period is in early 2011, when US bond rates rose on market optimism of a US economic recovery in the wake of QE2 implemented in late 2010. However, a domestic event partly underlying the EMS increase at the time was the anticipation and then delivery of two 0.25 percentage point policy rate increases by the ECB. The second period is in 2013, when US bond rates rose markedly in the wake of the Federal Reserve's comment on the likely tapering of its bond purchases, leading markets to anticipate a less expansionary US monetary policy stance. US rates rose also in 2015, the third period, when markets expeted the first interest rate increase by the Federal Reserve since the GFC, which was eventually implemented in December 2015. Corresponding to those periods of a less accommodative EMS, the PPI and IP-G fell relative to their counterfactuals from 2012, 2014, and 2016, ultimately evolving to levels below the counterfactuals. These events highlights that domestic monetary/financial conditions can be influenced materially by global develop- 
ments, and that central banks may have to be vigilant in offsetting such influences if they are not consistent with the intended stance of domestic monetary policy.

The component of EMS declines most likely corresponding to ECB policy can be associated with ECB UMP actions, i.e. the announcement of particular policies or comments that led the market to anticipate such announcements, when there were no influences counter to ECB intentions. The first notable episode in this regard are the declines in the EMS following the full allotment announcement on 15 October 2008, and again following a series of UMP programmes introduced from mid-2009 to mid-2010. ${ }^{21}$ Those EMS declines are associated with the PPI and IP-G rising relative to their counterfactuals from mid-2009, and higher-than-counterfactual levels from 2010-12. The second episode is the EMS decline following the series of UMP programmes in the second half of 2011, ${ }^{22}$ which is associated with the PPI and IP-G rising relative to their counterfactuals from around the beginning of 2013, and higher-than-counterfactual levels from 2013-2015. The third episode is the net EMS decline following the series of UMP programmes from mid-2014 to $2016,{ }^{23}$ which is associated with PPI inflation and the IP gap rising to above their counterfactuals in 2017. However, it is worthwhile bearing in mind that, even in these periods, the lower EMS may also have been influenced by falling US bond yields.

The first episode of the EMS decline provides the cleanest period for a counterfactual most attributable to ECB policy, given it is prior to influences from rising US bond yields. Hence, using the associated rise in inflation and the IP gap relative to the counterfactual from 2009 to early 2011, our results suggest that the ECB policies during the first episode resulted in PPI inflation being approximately 0.3 percentage points higher and the IP gap being approximately 1.2 percentage points higher than if those actions had not been

\footnotetext{
${ }^{21}$ The first Long-term Refinancing Operations (LTRO1) on 7 May 2009, the first Covered Bond Purchase Programme (CBBP1) on 4 June 2009, and the first Securities Market Programme (SMP1) on 10 May 2010.

${ }^{22}$ SMP2 on 7 August 2011, CBPP2 on 6 October 2011, and LTRO2 on 8 December 2012.

${ }^{23}$ The first targetted LTRO (TLTRO1) on 5 June 2014, the Asset-backed Securities Purchase Programme (ABSPP) on 4 September 2014, and the first large-scale Asset Purchase Programme (APP1) on 22 January 2015 (which notably began the Public Sector Purchase Programme, PSPP, to buy euro-area government bonds). An extension and increase to the APP were respectively announced on 3 December 2015 and 10 March 2016, and TLTRO2 was also announced on the latter date.
} 
instituted. The responses to inflation and the IP gap for the other periods of a lower EMS likely attributable to ECB policies are of similar magnitudes. Nevertheless, because our present framework is not designed to explicitly attribute the policy actions of the ECB to outcomes of the EMS and macroeconomic variables, we caution that the values we have mentioned above should not be taken too literally. That said, the discussion is useful to highlight potential approaches based on the EMS that could be used to make more explicit attributions of ECB policy to macroeconomic outcomes. For example, the EMS is available at a daily frequency, and using changes on ECB event days (or tighter windows, if necessary) would therefore allow those EMS shocks and their subsequent macroeconomic effects to be explicitly related to ECB UMP actions.

Figure 15 contains the results from our second counterfactual exercise, with EMS shocks to maintain the EMS at its neutral level of zero, relative to the realized values of the variables. In this case, the EMS is up to 3 percentage points below the counterfactual, and PPI inflation and the IP gap respectively rise 0.6 and 2.5 percentage points from their 2009 low-points to the end of our sample. However, these results should be interpreted with caution. The reason is essentially the Lucas critique: our TVP-VAR has been estimated from data in a policy environment where market participants would at least expect the policy rate to be lowered in response to lower inflation and a downturn in economic activity, and would also expect longer-maturity bond rates to fall. Hence, the true effects of neither of those things occurring, which is the implication of maintaining a zero EMS (if it were somehow possible for the central bank to maintain longer-maturtity bond rates close to the LNIR), is unlikely to be well-represented by our estimated TVPVAR. Nevertheless this exercise does usefully provide a clearer illustration of stimulus via the EMS to the macroeconomy. 


\section{Conclusion}

In this paper, we have introduced the concept of the EMS as a measure of monetary/financial stimulus that, unlike a policy rate, is designed to consistently reflect the overall stance of monetary policy across CMP and UMP environments. In both environments, the EMS quantifies monetary/financial stimulus as the sum of two components: (1) policy rate settings and their expectations relative to a long-horizon nominal natural interest rate; and (2) term premiums in longer-maturity interest rates. Importantly, we show that a model-free EMS can be obtained from long-maturity interest rates and survey data as a proxy for the long-horizon nominal natural rate, which avoids any issue of generated regressors in subsequent analysis.

We have then investigated the effect of the EMS policy on German and euro area macroeconomic variables using a small-scale VAR and TVP-VAR. We find that the EMS in both our VAR and TVP-VAR obtains plausible and stable structural relationships with prices and output developments across and within CMP and UMP environments. Specifically, tightening (easing) EMS shocks result in lower (higher) inflation and economic activity, and those responses are consistent over the sample period. These results suggest that the EMS provides a useful practical indication of monetary/financial stimulus in environments where interest rates are constrained by the effective lower bound. Indeed, even over just the CMP part of our sample, the EMS outperforms the traditional three-month interest rate, which is consistent with the EMS in principle reflecting more information on the overall monetary/financial stimulus compared to the short-maturity interest rate alone.

Our counterfactual results indicate that shocks to monetary/financial stimulus according to the EMS have mostly been expansionary since 2007, which has resulted in inflation and activity being higher than they otherwise might have been. However, because the EMS is influenced by ECB policy actions and non-ECB aspects, such as spillovers from US bond yields, we cannot attribute the counterfactual results explicitly to the ECB. We 
can, however, highlight periods where ECB actions made the greatest influence on the EMS relative to its counterfactual, and associate those with elevated outcomes of inflation and the output gap relative to their counterfactuals.

In summary, the EMS concept and its practical inception we have introduced in this paper shows promise as a monetary/financial stimulus measure over both CMP and UMP periods. One area for future research will be to use high-frequency analysis to better attribute EMS movements and their effects on macroeconomic variables to ECB policy actions. 


\section{References}

Adrian, T., R. Crump, B. Mills, and E. Moench (2014, 5 August). Treasury term premia: 1961-present. Federal Reserve Bank of New York, Liberty Street Economics.

Aruoba, S. (2016). Term structures of inflation expectations and expectations of real interest rates. Working Paper, Federal Reserve Bank of Philidelphia 18-09.

Barro, R. and X. Sala-i-Martin (2004). Economic Growth, Second Edition. MIT Press.

Baumeister, C. and G. Peersman (2013). Time-varying effects of oil supply shocks on the US economy. American Economic Journal: Macroeconomics 5(4), 1-28.

Bernanke, B. (2017). Monetary policy in a new era. Peterson Institute Conference, October 12-13, 2017.

Bullard, J. (2012). Shadow Interest Rates and the Stance of U.S. Monetary Policy. Speech at the Annual Conference, Olin Business School, Washington University in St. Louis, 8 November 2012.

URL: http://www.stlouisfed.org/newsroom/displayNews.cfm?article=1574.

Bullard, J. (2013). Perspectives on the Current Stance of Monetary Policy. Speech at the NYU Stern, Center for Global Economy and Business, 21 February 2013. URL: http://www.prweb.com/releases/2013/2/prweb10455633.htm.

Candelon, B. and H. Lütkepohl (2001). On the reliability of Chow-type tests for parameter constancy in multivariate dynamic models. Economics Letters 73(2), 155-160.

Christensen, J. and G. Rudebusch (2015). Estimating shadow-rate term structure models with near-zero yields. Journal of Financial Econometrics 13(2), 226-259.

Christiano, L. J., M. Eichenbaum, and C. Evans (1996). The effects of monetary policy shocks: Evidence from the flow of funds. Review of Economics and Statistics 78(1), $16-34$.

Clarida, R., J. Gali, and M. Gertler (1998). Monetary policy rules in practice: Some international evidence. European Economic Review 42(6), 1033 - 1067.

Elbourne, A. and J. de Haan (2009). Modeling monetary policy transmission in acceding countries: Vector autoregression versus structural vector autoregression. Emerging Markets Finance and Trade 45(2), 4-20.

Engel, C. and K. D. West (2006). Taylor rules and the Deutschmark: Dollar real exchange rate. Journal of Money, Credit and Banking 38(5), 1175-1194.

Evans, C. and D. Marshall (1998). Monetary policy and the term structure of nominal interest rates: evidence and theory. Carnegie-Rochester Conference Series on Public Policy 49, 53-111.

Filipović, D. (2009). Term-Structure Models: A Graduate Course. Springer. 
Francis, N., L. E. Jackson, and M. T. Owyang (2014). How has empirical monetary policy analysis changed after the financial crisis? Working Papers 2014-19, Federal Reserve Bank of St. Louis.

Gertler, M. and P. Karadi (2015). Monetary policy surprises, credit costs, and economic activity. American Economic Journal: Macroeconomics 7(1), 44-76.

Grilli, V. and N. Roubini (1996). Liquidity models in open economies: Theory and empirical evidence. European Economic Review 40(3-5), 847-859.

Gürkaynak, R., B. Sack, and E. Swanson (2005). Do actions speak louder than words? The response of asset prices to monetary policy actions and statements. International Journal of Central Banking 1(1), 55-93.

Holston, K., T. Laubach, and J. Williams (2017). Measuring the natural rate of interest: International trends and determinants. Journal of International Economics 108, S59S75.

Kim, D. and K. Singleton (2012). Term structure models and the zero bound: an empirical investigation of Japanese yields. Journal of Econometrics 170(1), 32-49.

Korobilis, D. (2014). Estimating a TVP-FAVAR with a latent financial conditions index for the US. Mimeo, University of Glasgow.

Krippner, L. (2011). Modifying Gaussian term structure models when interest rates are near the zero lower bound. Discussion paper, Centre for Applied Macroeconomic Analysis 36/2011.

Krippner, L. (2013). Measuring the stance of monetary policy in zero lower bound environments. Economics Letters 118(1), 135-138.

Krippner, L. (2014). Measuring the stance of monetary policy in conventional and unconventional environments. Working Paper, Centre for Applied Macroeconomic Analysis 6/2014.

Krippner, L. (2015). Zero Lower Bound Term Structure Modeling: A Practitioner's Guide. Palgrave-Macmillan.

Kucharcukova, O., P. Claeys, and B. Vasicek (2016). Spillover of the ECB's monetary policy outside the euro area: How different is conventional from unconventional policy? Journal of Policy Modeling 38(2), 199-225.

Laubach, T. and J. Williams (2015). Measuring the natural rate of interest redux. Working Paper, Federal Reserve Bank of San Francisco 2015-16.

Lombardi, M. and F. Zhu (2014). A shadow policy rate to calibrate US monetary policy at the zero lower bound. Working Paper, Bank of International Settlements 452.

Mouabbi, S. and J. Sahuc (2018). Evaluating the macroeconomic effects of the ECB's unconventional monetary policies. Working Paper. 
Nelson, C. and A. Siegel (1987). Parsimonious modelling of yield curves. Journal of Business 60(4), 473-489.

Primiceri, G. E. (2005). Time varying structural vector autoregressions and monetary policy. Review of Economic Studies 72(3), 821-852.

Ravn, M. O. and H. Uhlig (2001). On adjusting the HP-filter for the frequency of observations. CESifo Working Paper Series 479.

Sims, C. A. (1992). Interpreting the macroeconomic time series facts: The effects of monetary policy. European Economic Review 36(5), 975-1000.

Taylor, M. P. and E. Davradakis (2006). Interest rate setting and inflation targeting: Evidence of a nonlinear Taylor rule for the United Kingdom. Studies in Nonlinear Dynamics \& Econometrics 10(4), 1-20.

von Borstel, J., S. Eickmeier, and L. Krippner (2016). The interest rate pass-through in the euro area before and during the sovereign debt crisis. Journal of International Money and Finance 68, 386-402.

Walsh, C. (2003). Monetary Theory and Policy, Second Edition. MIT Press.

Weale, M. and T. Wieladek (2016). What are the macroeconomic effects of asset purchases? Journal of Monetary Economics 79, 81-93.

Williams, J. (2011). Unconventional monetary policy: lessons from the past three years. Federal Reserve Bank of San Francisco Economic Letter 2011-31.

Woodford, M. (2012). Methods of policy accommodation at the interest-rate lower bound. Speech at Jackson Hole Symposium, 20 August 2012. URL: www.kc.frb.org/publicat/sympos/2012/mw.pdf.

Wu, J. C. and F. D. Xia (2016). Measuring the macroeconomic impact of monetary policy at the zero lower bound. Journal of Money, Credit, and Banking 48(2-3), 253-291. 


\section{Table from main body of the paper}

Table 1: VAR structural break tests

\begin{tabular}{lcc}
\hline VAR & Breakpoint test & Split sample test \\
EMS & $188.82^{* * *}$ & $149.74^{* * *}$ \\
3-month rate & $221.79^{* * *}$ & $192.42^{* * *}$ \\
SSR & $197.23^{* * *}$ & $159.64^{* * *}$ \\
\hline Note: $* * *$ indicates significance at the 1 percent level \\
(the 1 percent critical values are 109.95 and 98.02).
\end{tabular}

\section{Figures from main body of the paper}

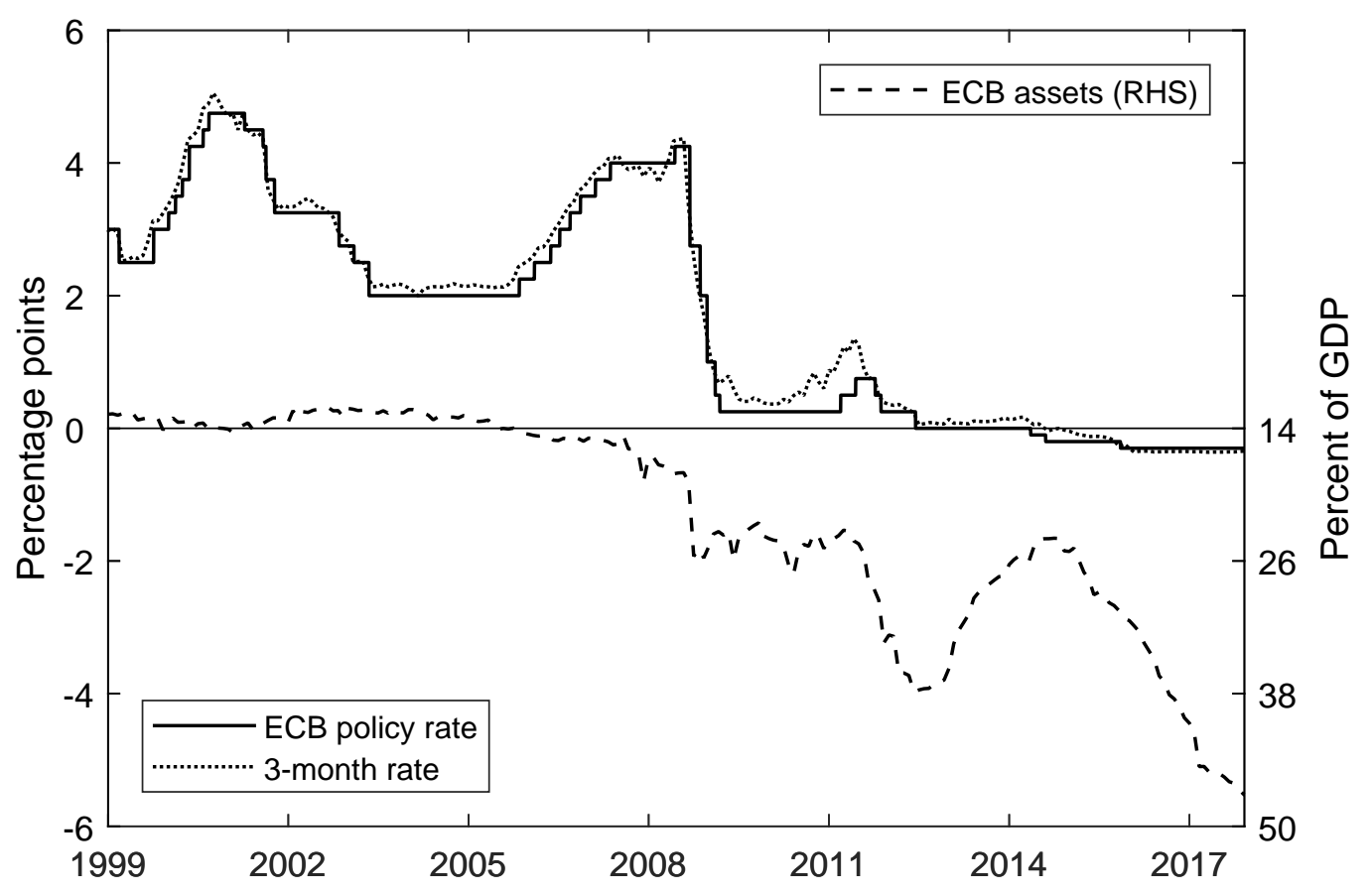

Figure 1: ECB policy rate (Main Refinancing Operations [MRO] rate, then deposit rate from 8 October 2008 when full allotment for MROs was announced), 3-month rate, and assets held on the ECB balance sheet. 

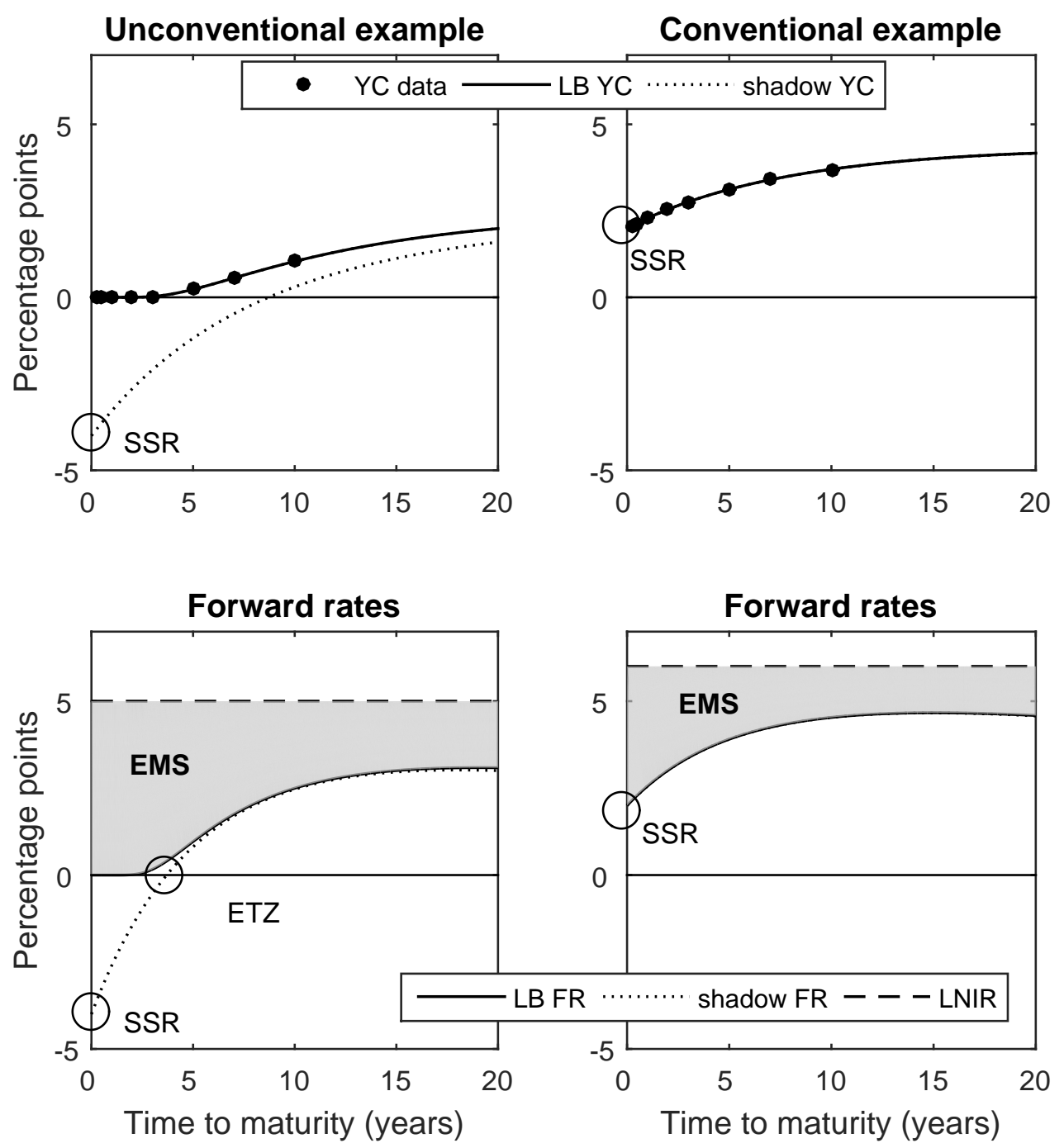

Figure 2: Yield curve data and the concept of the EMS. YC is yield curve, LB is lower bound, FR is forward rate, and LNIR is the long-horizon nominal natural interest rate. SSR is the Shadow Short Rate, which we later test as a measure of monetary/financial stimulus. ETZ is the Expected Time to Zero, a measure of expected "lift off", which has been discussed in the introduction and is not used elsewhere in this paper. 


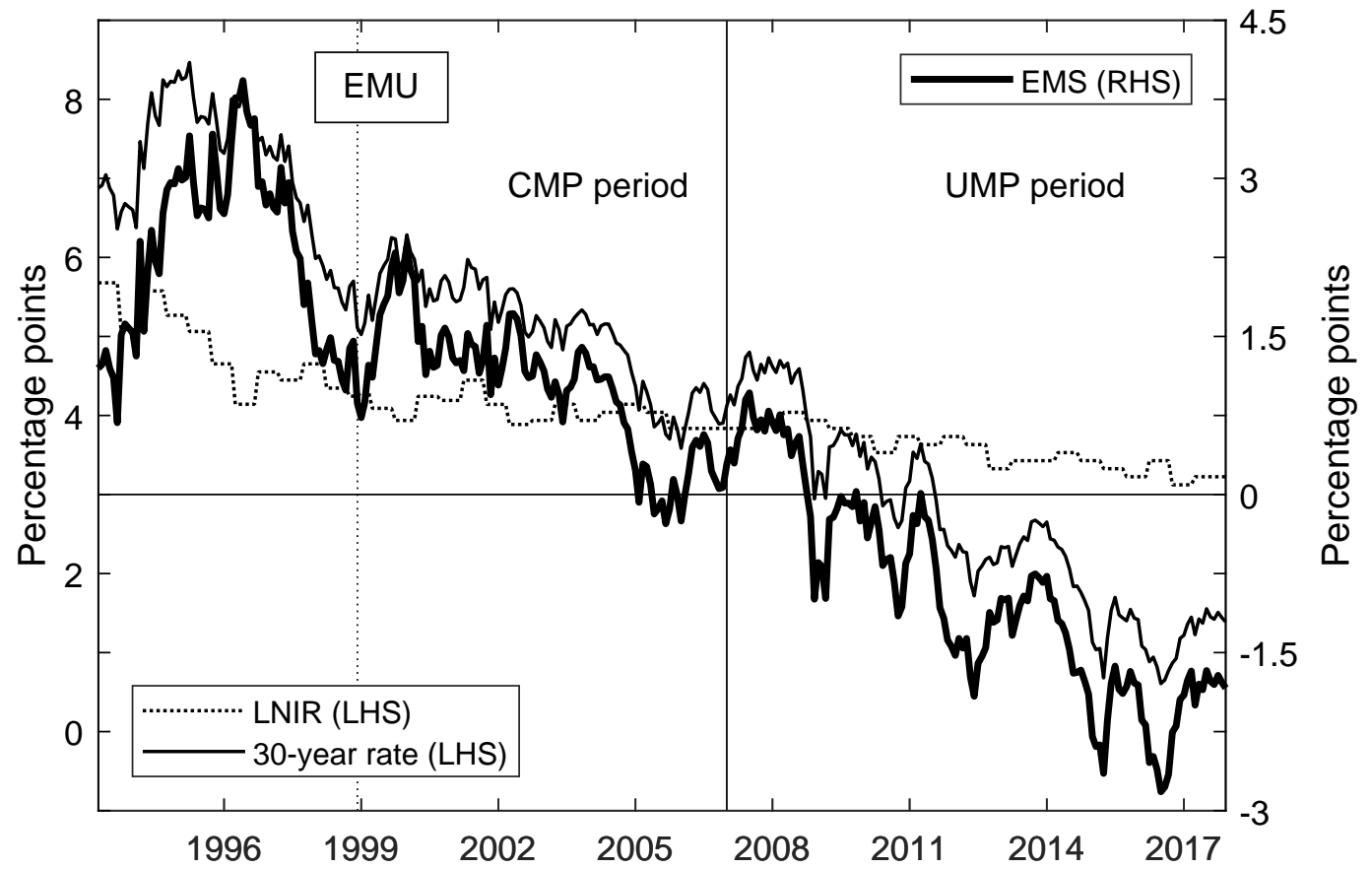

Figure 3: Time series of the LNIR, the 30-year rate, and the associated EMS. 

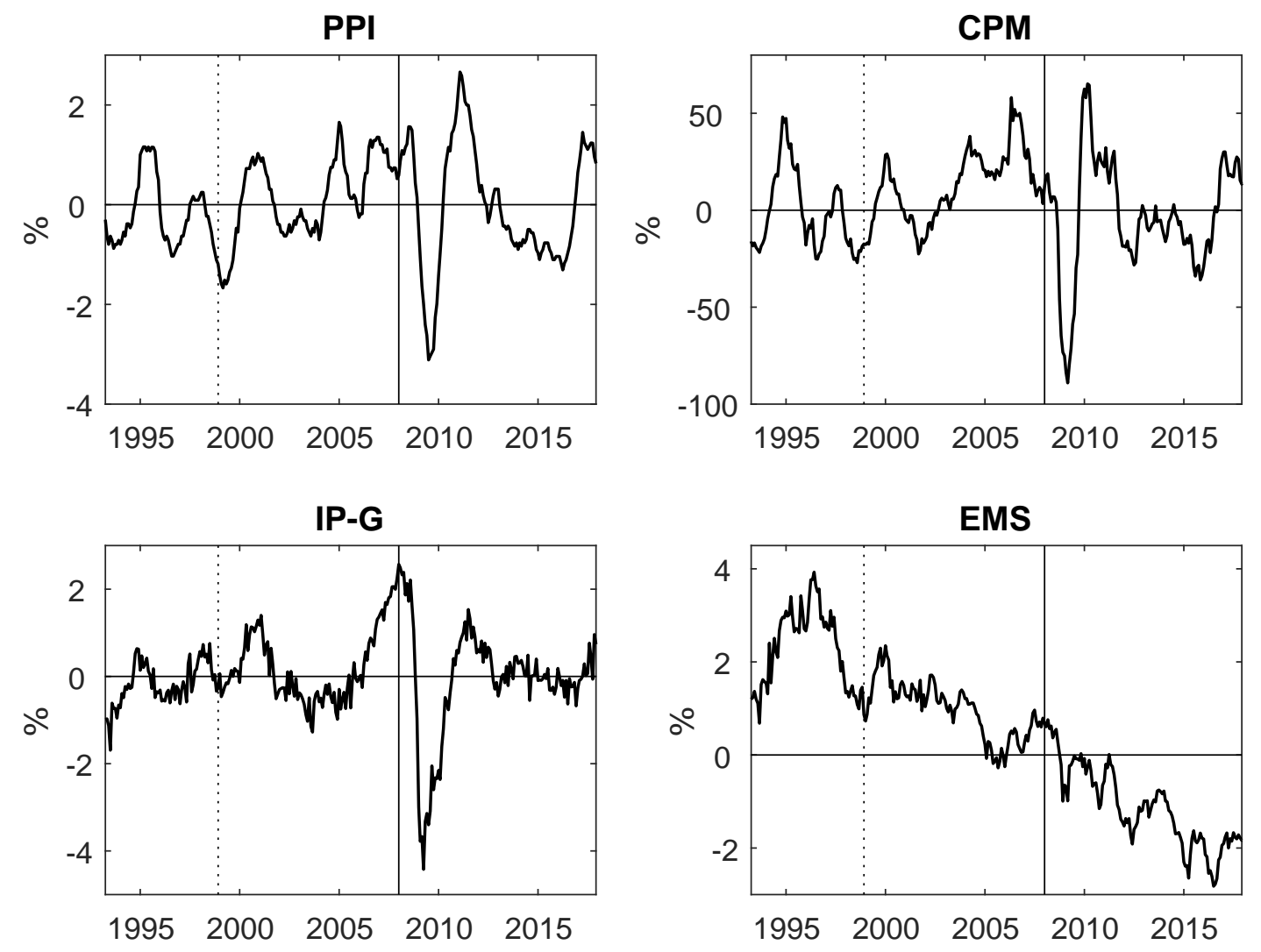

Figure 4: The macroeconomic and commodity price data for our benchmark estimations. PPI is the annual inflation rate of ex-energy inland producer prices, CPM is the annual inflation rate of the World Bank metal and mineral price index, IP-G is the log-level deviation of industrial production from its time-varying trend, and EMS is our Effective Monetary Stimulus series. The vertical dotted and solid lines are, respectively, January 1999 (to indicate the introduction of the euro) and January 2008 (to indicate our divide between the CMP and UMP periods). 


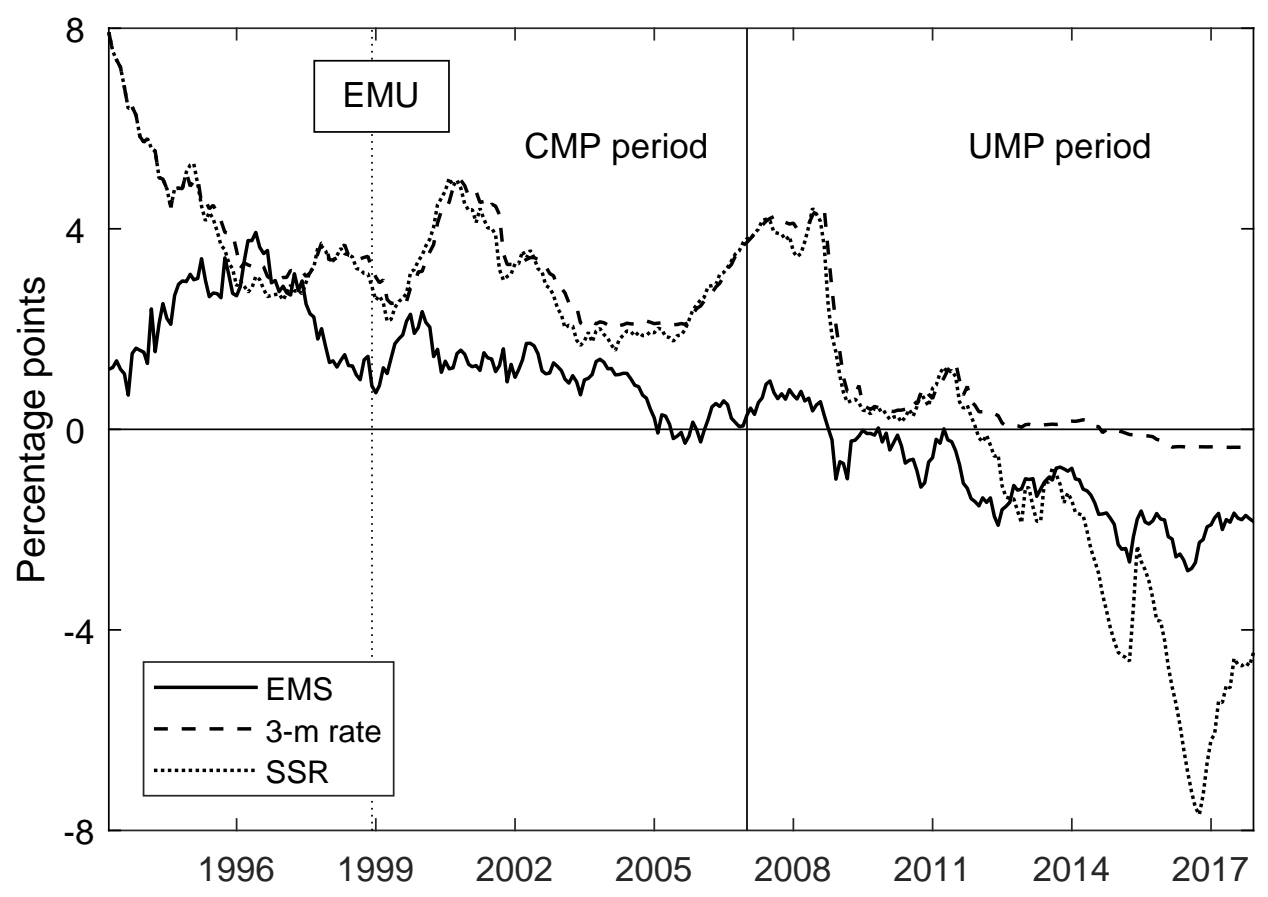

Figure 5: The EMS, 3-month rate, and SSR, that we use as the monetary/financial variable in our VAR and TVP-VAR. 

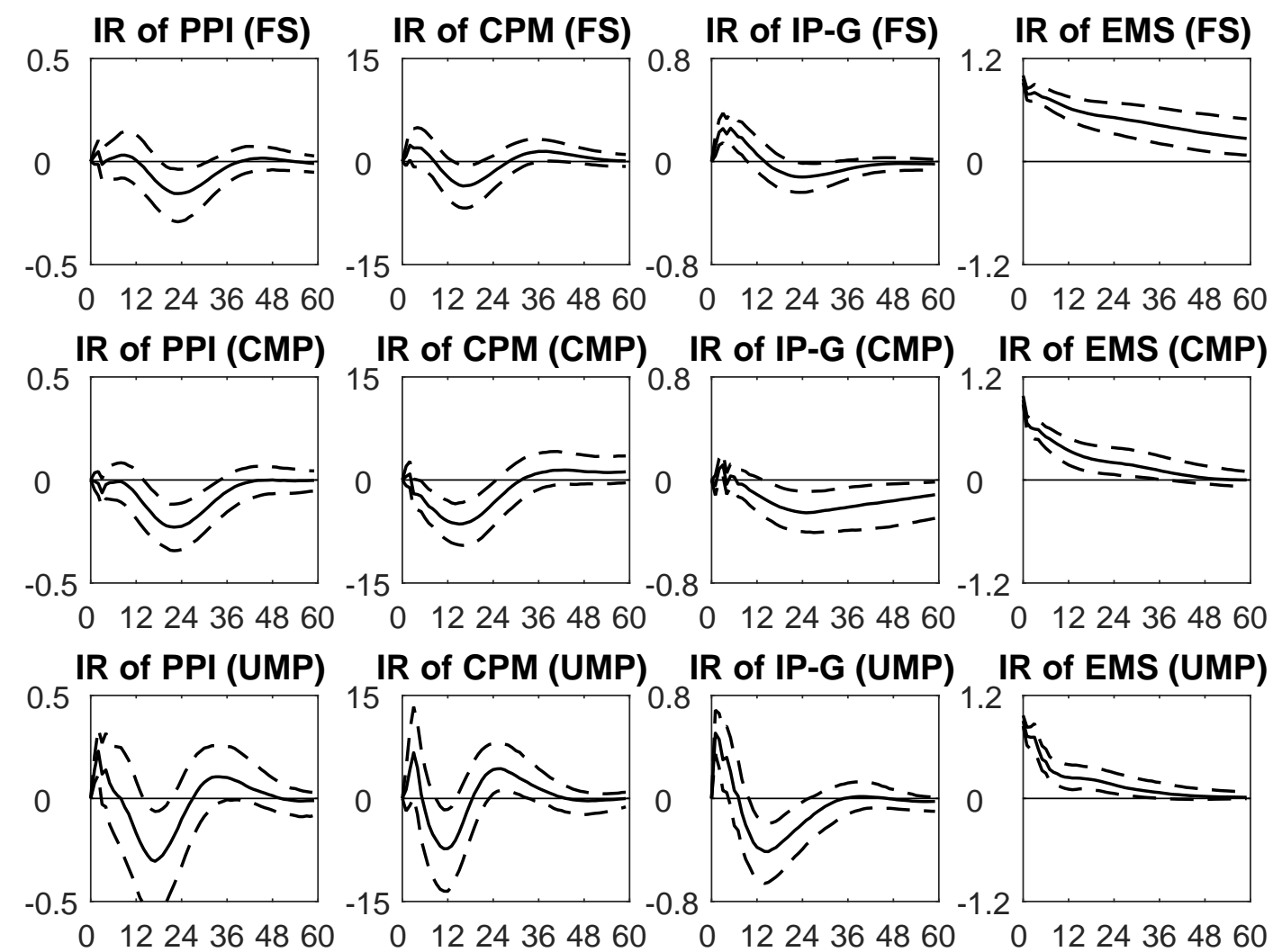

Figure 6: Impulse responses from the standard VAR using the EMS as the monetary/financial variable. 

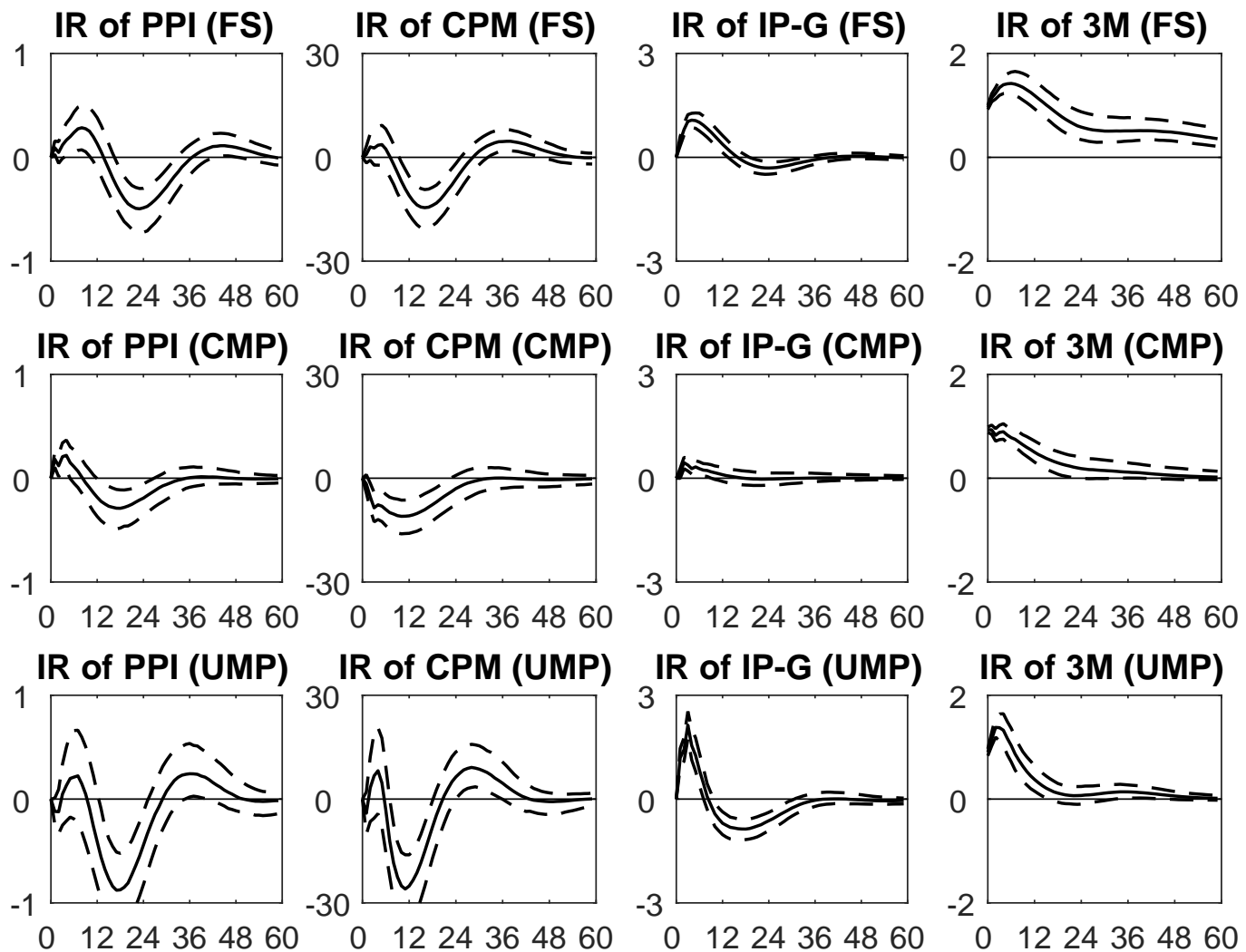

Figure 7: Impulse responses from the standard VAR using the 3-month rate as the monetary/financial variable. 

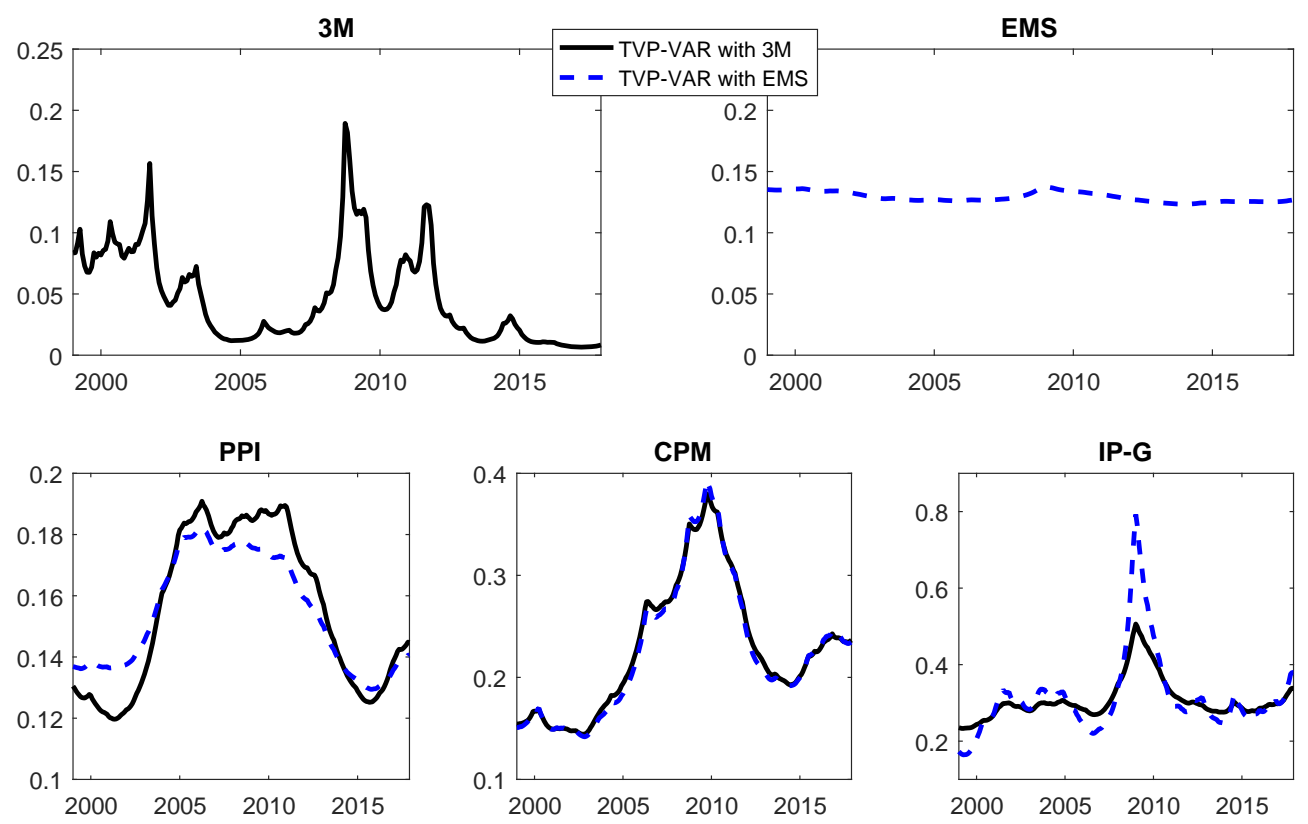

Figure 8: Posterior means of the time-varying standard deviations of the forecast residuals of the VAR. Blue-dashed lines refer to a VAR featuring the EMS as monetary policy indicator; black lines refer to a VAR with the short rate instead of the EMS measure.
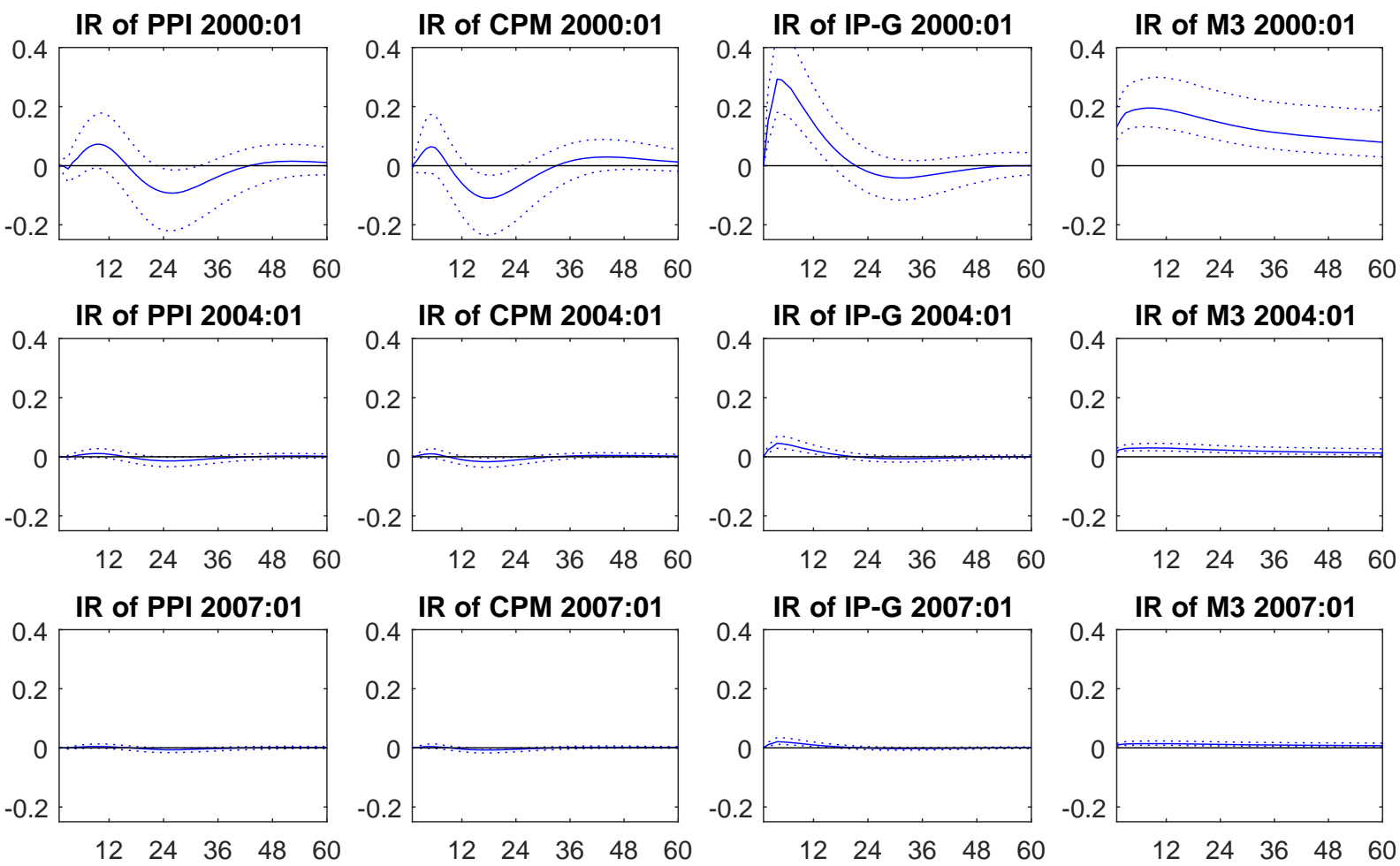

Figure 9: Impulse responses to a 3-month rate shock in a non-zero lower bound sample (19992008). The upper row depicts the responses in January 2000, the middle row those in January 2004, and the lower row those from January 2007. Dashed lines indicate $16 \%$ and $84 \%$ confidence intervals. 

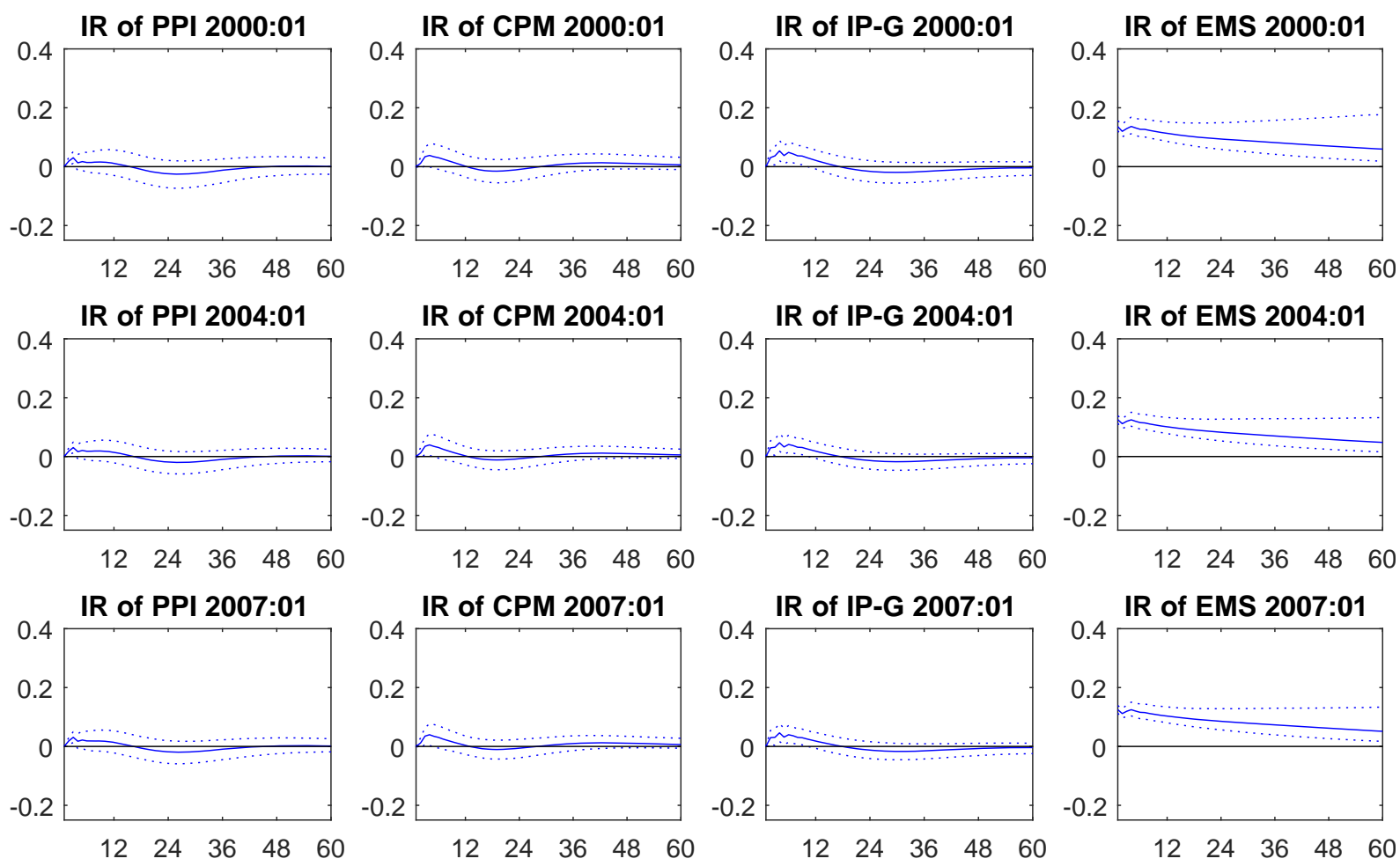

Figure 10: Impulse responses to an EMS shock in a non-zero lower bound sample (1999-2008). The upper row depicts the responses in January 2000, the middle row those in January 2004, and the lower row those from January 2007. Dashed lines indicate $16 \%$ and $84 \%$ confidence intervals. 

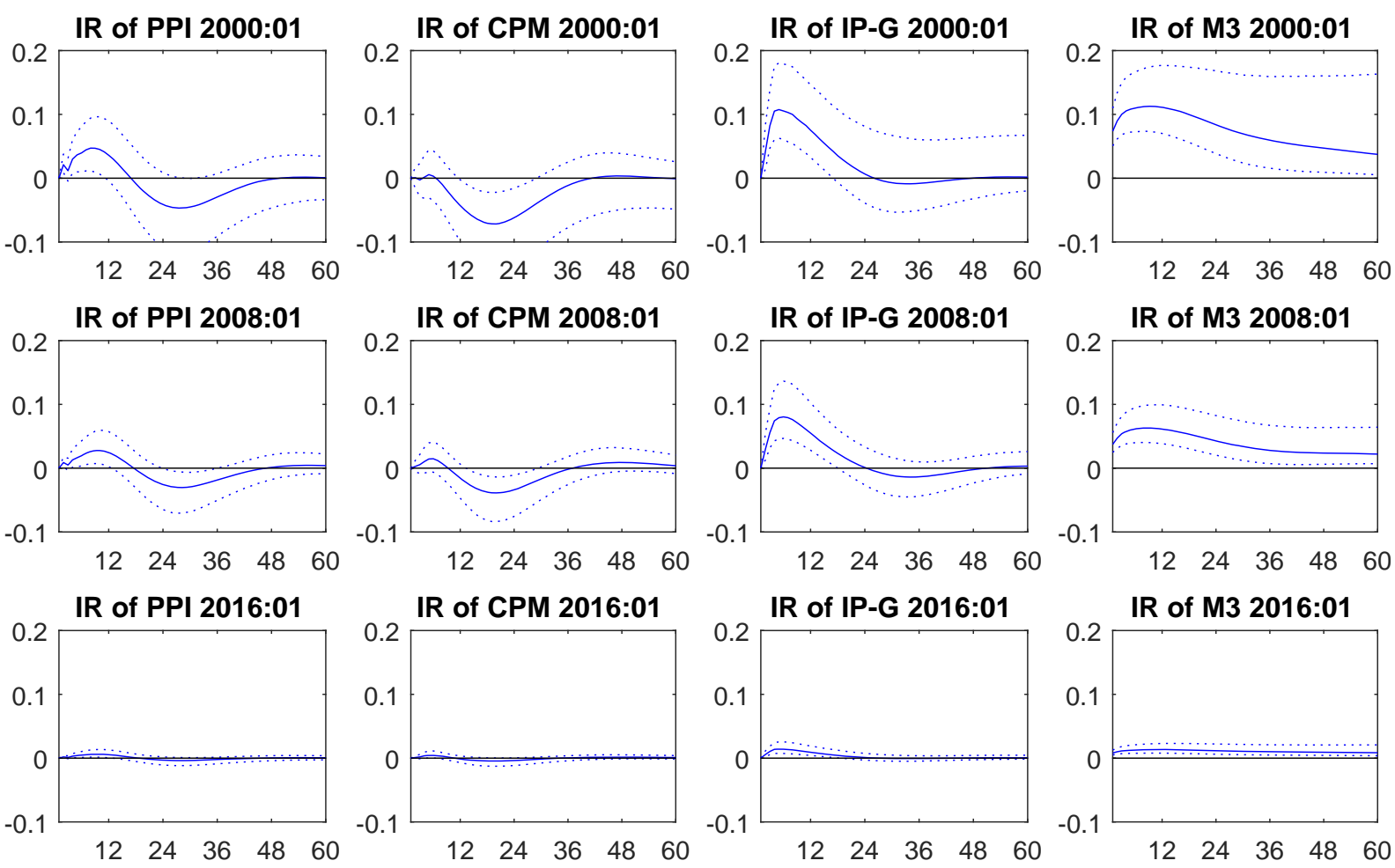

Figure 11: Impulse responses to a 3-month interest rate shock in a sample covering both a non-zero lower bound period and a period in which the lower bound is binding (1999-2017). The upper row depicts the responses in January 2000, the middle row those in January 2008, and the lower row those from January 2016. Dashed lines indicate $16 \%$ and $84 \%$ confidence intervals. 

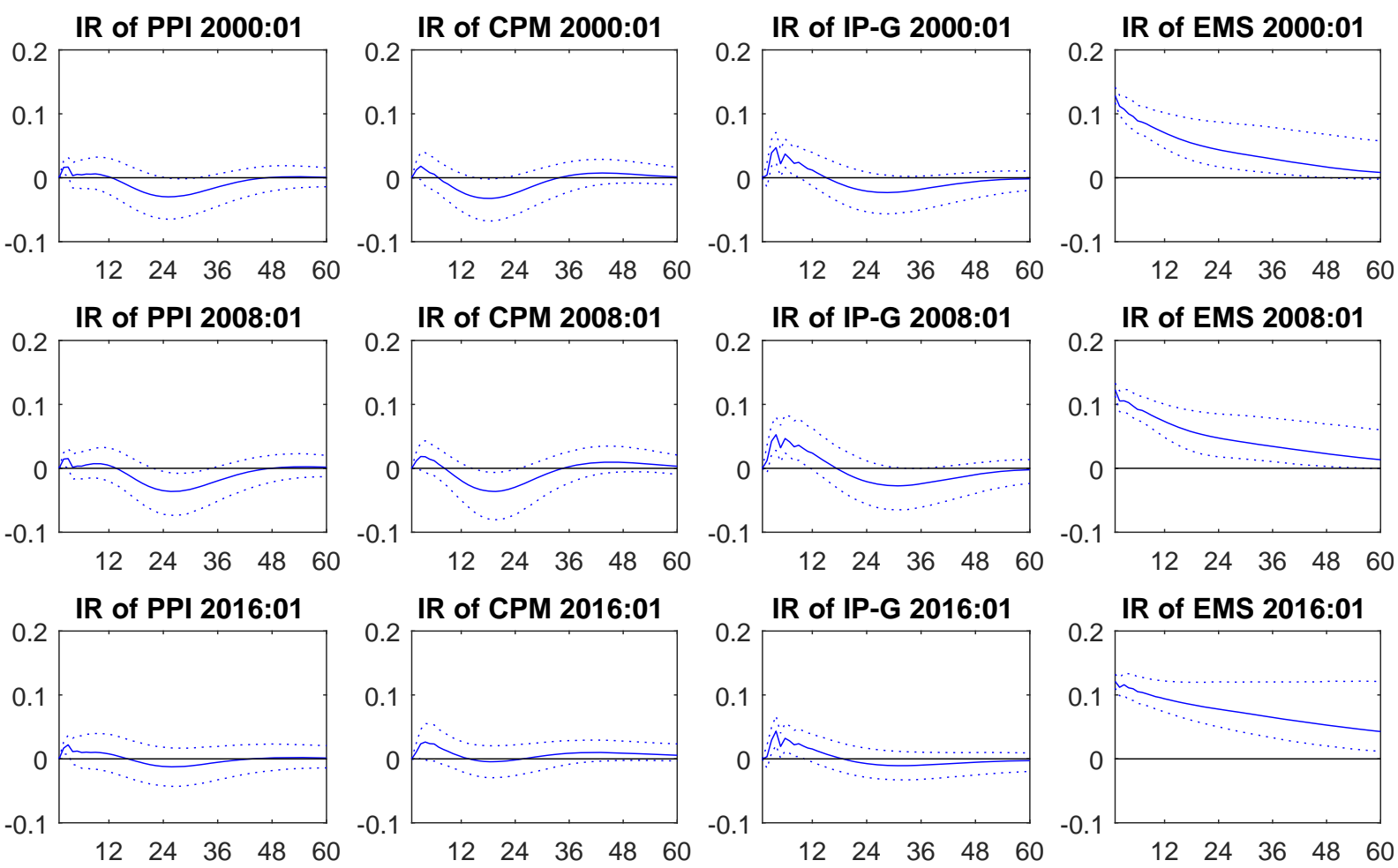

Figure 12: Impulse responses to an EMS shock in a sample covering both a non-zero lower bound period and a period in which the lower bound is binding (1999-2017). The upper row depicts the responses in January 2000, the middle row those in January 2008, and the lower row those from January 2016. Dashed lines indicate $16 \%$ and $84 \%$ confidence intervals. 


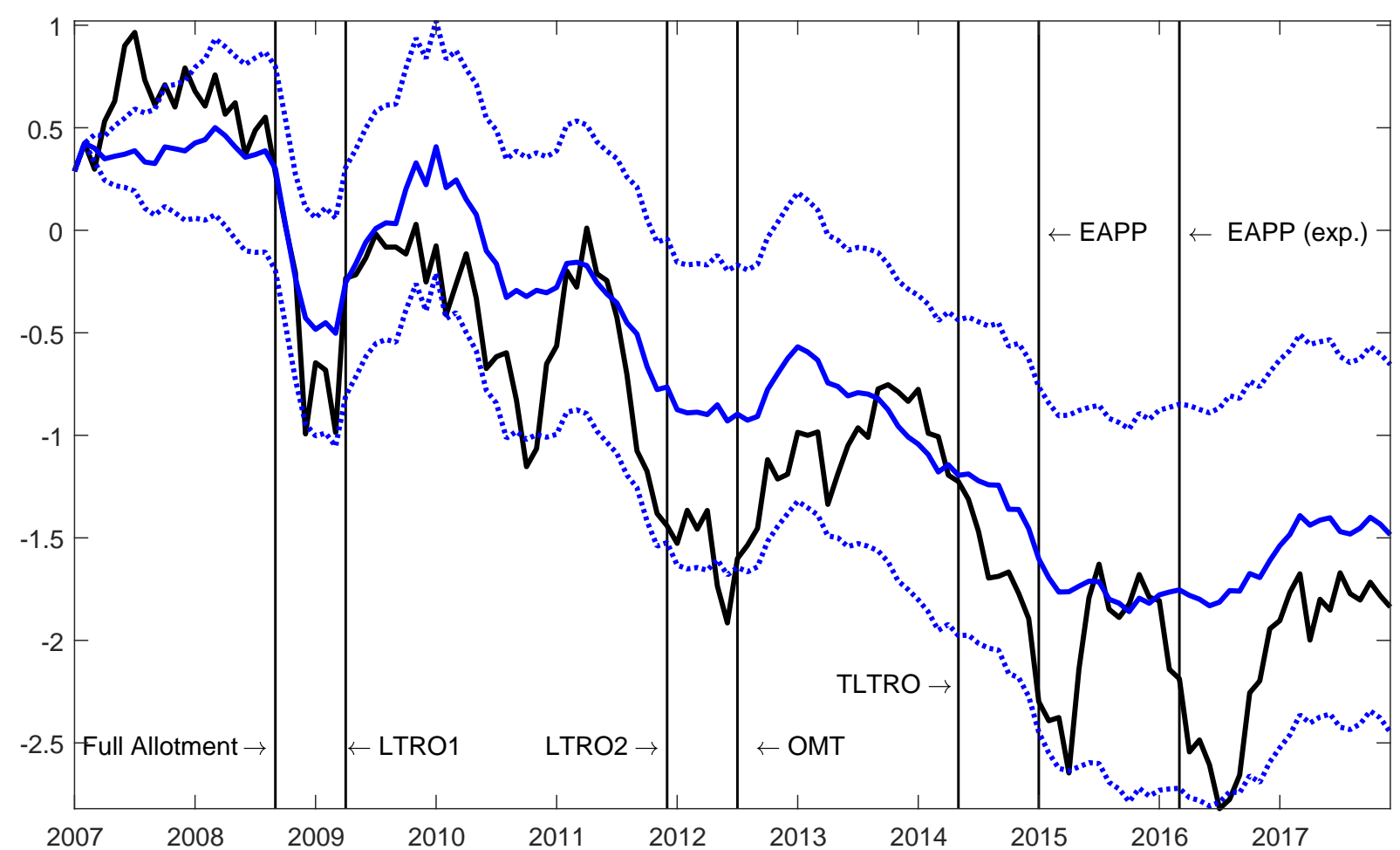

Figure 13: Realized EMS (black line) and the counterfactual indicator (blue line) assuming no EMS shocks had occurred. Dashed lines indicate $16 \%$ and $84 \%$ confidence intervals.
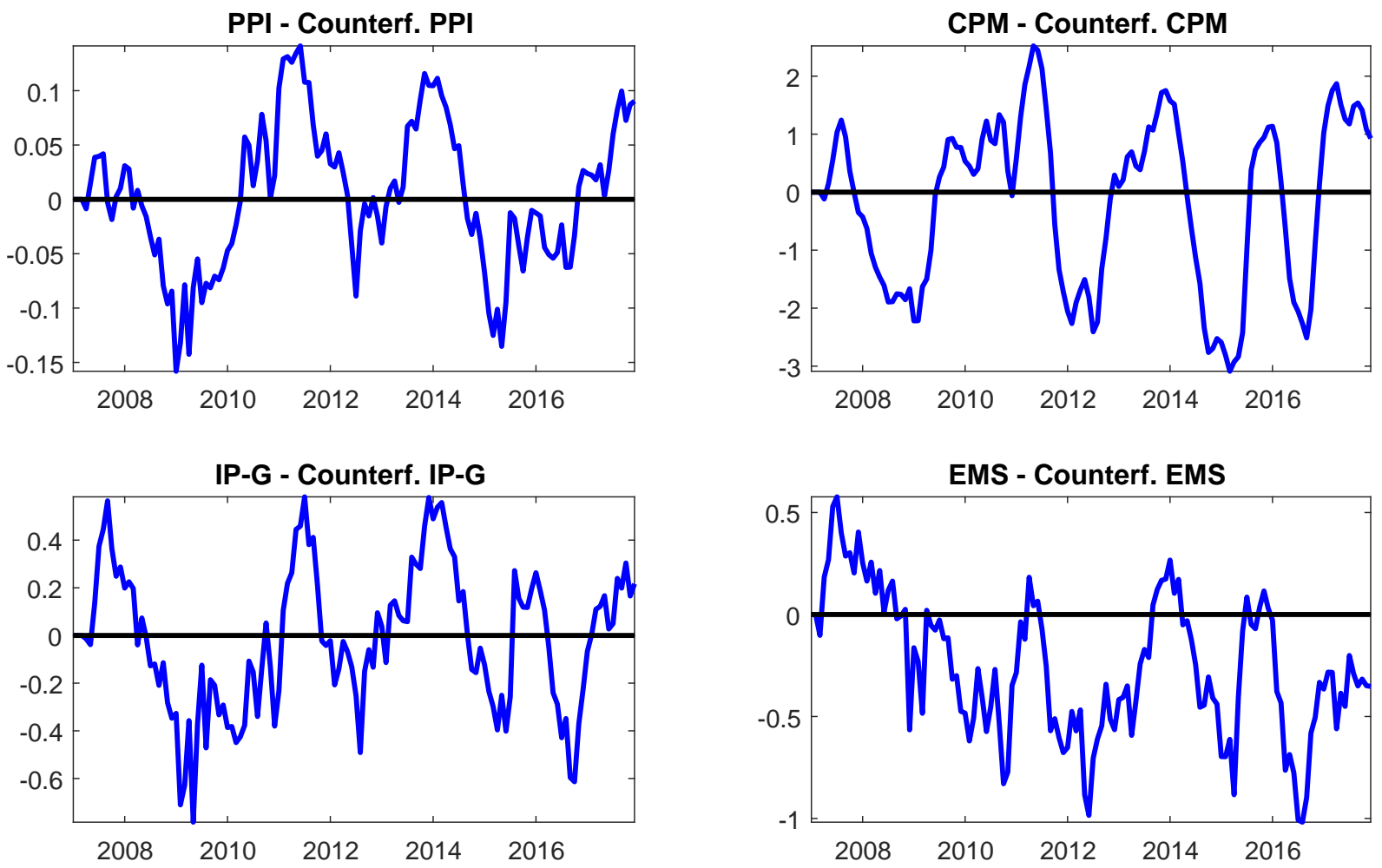

Figure 14: Difference between the realized values of variables and their counterfactual values which would have prevailed if no EMS shocks had occurred. Units are percentage points for the EMS, and percent for the other variables. 
PPI - Counterf. PPI

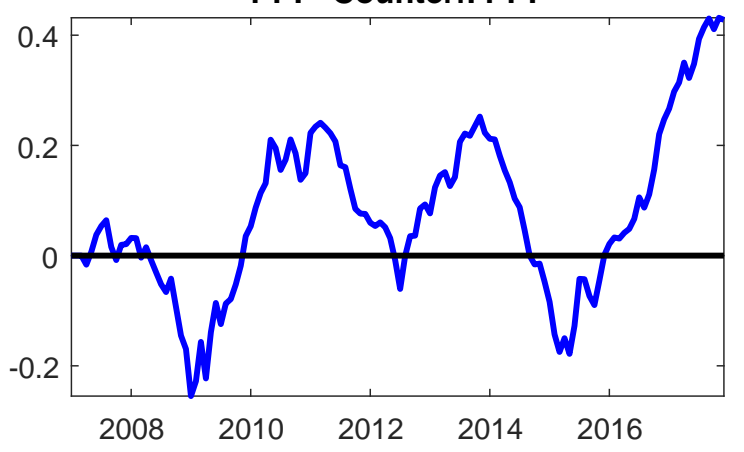

IP-G - Counterf. IP-G

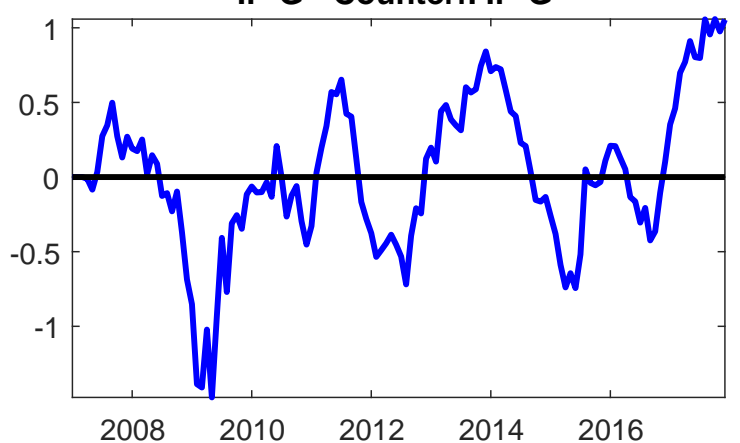

CPM - Counterf. CPM

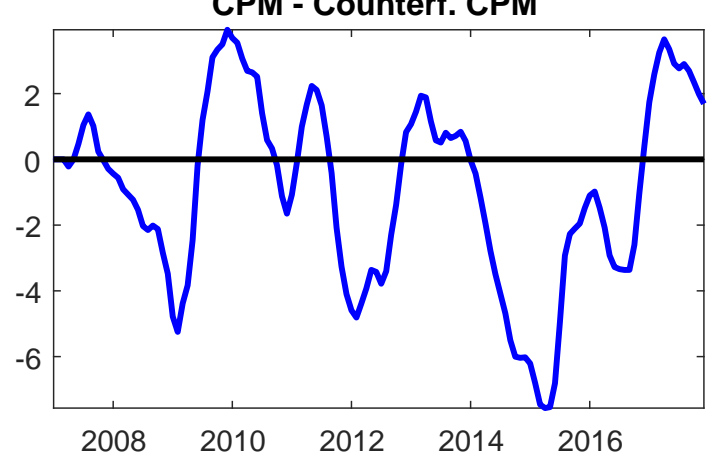

EMS - Counterf. EMS

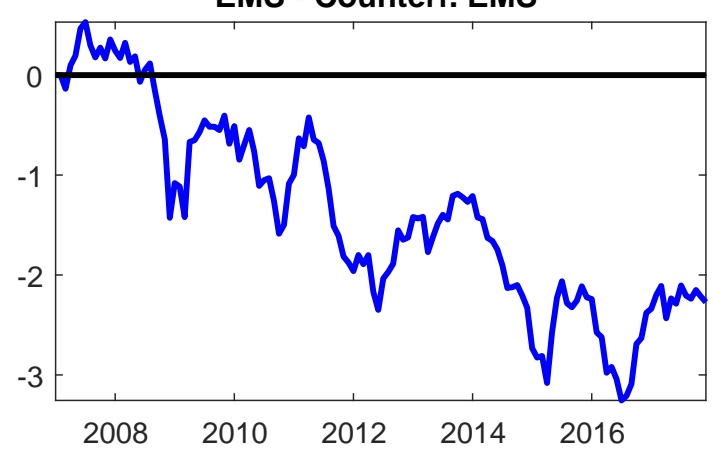

Figure 15: Difference between the realized values of variables and their counterfactual values which would have prevailed if EMS shocks had maintained the EMS at zero. Units are percentage points for the EMS, and percent for the other variables. 


\section{A The model}

The main model we use for our investigation is the time-varying parameter VAR (TVPVAR) of Primiceri (2005), which allows for both changes in the structural relationships of the VAR over time and also changes in volatility. ${ }^{24}$ Those aspects make it highly applicable to our investigation because the sample period that we consider covers distinctly different environments at different parts of the sample.

We consider a VAR process of the form:

$$
y_{t}=c_{t}+B_{1, t} y_{t-1}+\ldots+B_{k, t} y_{t-k}+u_{t} .
$$

where $y_{t}$ is a vector of macroeconomic and monetary/financial variables that we will outline in section 4 . The coefficients $B_{i, t}, i=1, \ldots, k$ and the innovations $u_{t}$ can vary over time. We use $k=4$ lags in our application, as suggested by the Akaike information criterion from a standard VAR. The variance-covariance matrix of the residuals $u_{t}, \Omega_{t}$, may be decomposed as:

$$
A_{t} \Omega_{t} A_{t}=\Sigma_{t} \Sigma_{t}^{\prime}
$$

where $A_{t}$ is a lower triangular matrix with elements $\alpha_{i j, t}, j=1, \ldots, k$, in the lower triangle and ones on the main diagonal. The forecast error variance matrix, $\Sigma_{t}$, is a diagonal matrix with the time-varying elements $\sigma_{1, t}, \ldots, \sigma_{n, t}$ on its main diagonal. Note that the variance changes in any state variable can transmit to the other state variables because the matrix $A$ is not diagonal.

The number of parameters to be estimated is kept small by assuming that the time variation of the parameters can be described by (geometric) random walks, i.e.:

$$
\begin{aligned}
c_{t} & =c_{t-1}+\omega_{t}, \\
B_{t} & =B_{t-1}+\nu_{t}, \\
\alpha_{t} & =\alpha_{t-1}+\zeta_{t}, \\
\log \left(\sigma_{t}\right) & =\log \left(\sigma_{t-1}\right)+\eta_{t} .
\end{aligned}
$$

where $B_{t}$ represents the vectorized matrix of coefficients $B_{1, t}, \ldots, B_{k, t}$, and the vectors $\alpha_{t}$ and $\sigma_{t}$ respectively contain the free or non-zero elements of $A_{t}$ or $\Sigma_{t}$, respectively. The variances of the residuals are assumed to be normally distributed and uncorrelated with each other.

Our prior specifications are in line with those in Primiceri (2005) and we use a training sample, that we outline in section 4, to define the priors. Korobilis (2014) stresses that a training sample specification has a particular advantage of numerical stability when used for estimating time-varying-parameter models. We use OLS point estimates of parameters over the training sample as hyperparameters.

The prior distribution of the coefficient matrix of the VAR equation, $B_{i, t}$, is assumed to be normal, and its first two moments are set equal to the OLS estimates on the training

\footnotetext{
${ }^{24}$ We refer readers to Primiceri (2005) for a detailed discussion and a documentation of the estimation procedure. We are grateful to Gary Koop for sharing his code for Primiceri (2005) on his website; see https://sites.google.com/site/garykoop/home.
} 
sample:

$$
B_{0} \sim N\left(\hat{B}_{T S}, 5 * V\left(\hat{B}_{T S}\right)\right)
$$

The prior distribution of $\sigma_{t}$, the diagonal elements of the variance matrix of the VAR equation, is normal with the mean of the corresponding training sample OLS estimate and a diagonal variance matrix:

$$
\log \left(\sigma_{0}\right) \sim N\left(\log \left(\hat{\sigma}_{T S}\right), 5 * I_{n}\right)
$$

Analogously, for the prior distribution of $A_{t}$ we assume:

$$
A_{0} \sim N\left(\hat{A}_{T S}, 5 * V\left(\hat{A}_{T S}\right)\right)
$$

where $V\left(\hat{A}_{T S}\right)$ is the variance of $\hat{A}_{T S}$ in the training sample.

For $S$ and $Q$, the variance covariance matrices of $\zeta_{t}$ and $B_{i, t}$, respectively, inverseWishart distributions are assumed:

$$
\begin{gathered}
S \sim i W\left(k_{S}^{2} * 5 * V\left(\hat{A}_{T S}\right), 5\right) \\
Q \sim i W\left(k_{Q}^{2} * 69 * V\left(\hat{B}_{T S}\right), 69\right)
\end{gathered}
$$

Because we incorporate $M=4$ state variables, we have to assume at least $M+1=5$ degrees of freedom for the distribution of $S$; a lower number of degrees of freedom would result in the mean of the inverse Wishart distribution not being defined. Similarly, we assume 69 degrees of freedom for the distribution of $Q$, because $\hat{B}_{T S}$ has $M+M^{2} * k=68$ elements. Essentially, our choice for the degrees of freedom implies that the priors are as least informative as possible.

For $W$, the variance covariance matrices of $\eta_{t}$, we assume an inverse-Gamma distribution:

$$
W \sim i G\left(k_{W}^{2} * 5 * I_{n}, 5\right)
$$

To simplify the estimation, as in Primiceri (2005), we also adopt the assumption that $S$ has a block structure.

The prior beliefs about time variation in the covariance matrix of the processes of $Q$, $\alpha_{t}$ and $\log \left(\sigma_{t}\right)$ are set as in Primiceri $(2005), k_{Q}=0.01, k_{S}=0.1$ and $k_{W}=0.01$. We find that the results are only negligibly affected by moderate changes in these parameters. Primiceri (2005) documents thoroughly that the posterior inference is not very sensitive to choices of these hyperparameters. 


\section{B Additional figures (possibly for online appendix)}
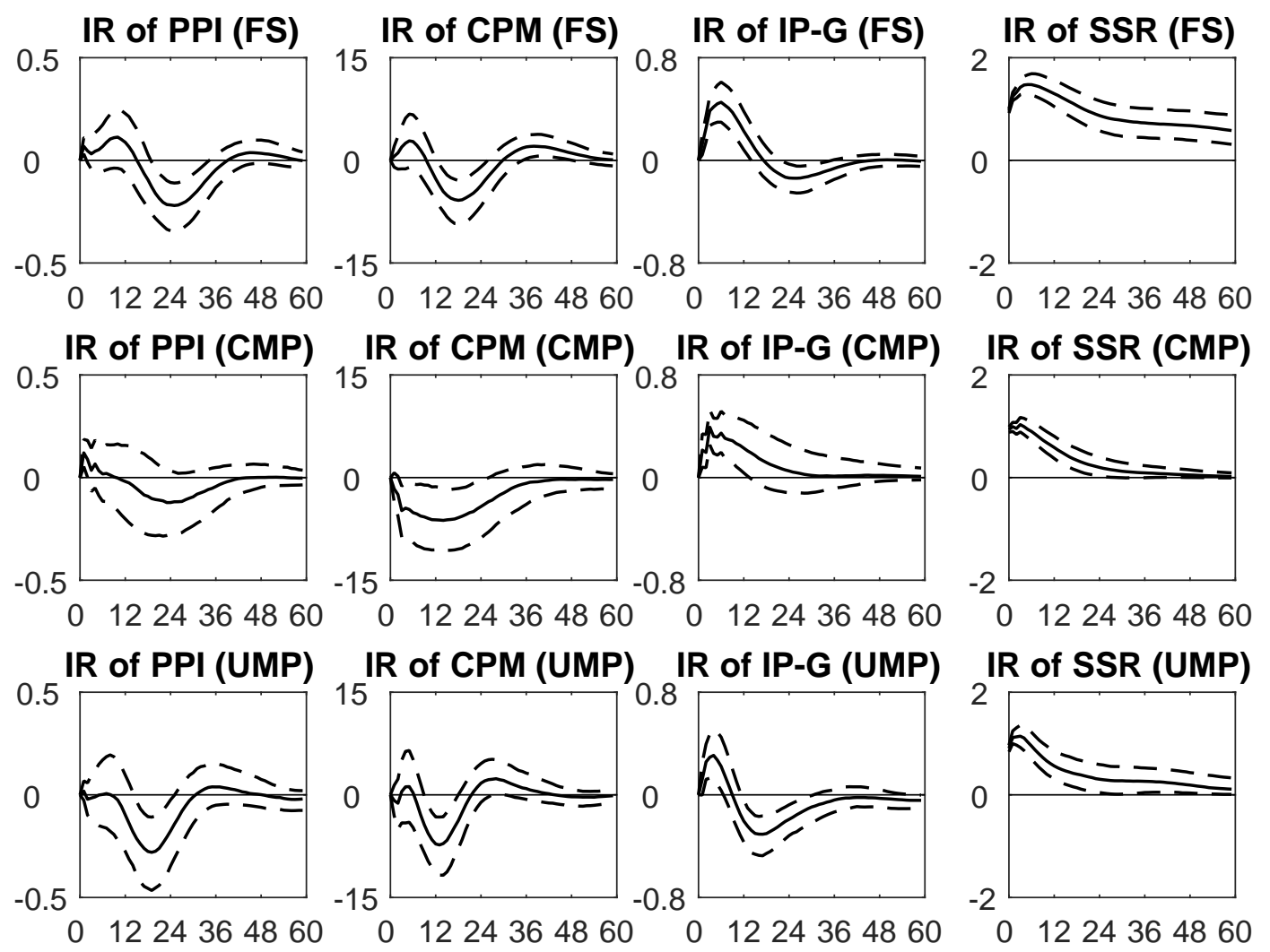

Figure 16: Impulse responses from the standard VAR using the SSR as the monetary/financial variable. 
Intercept: PPI

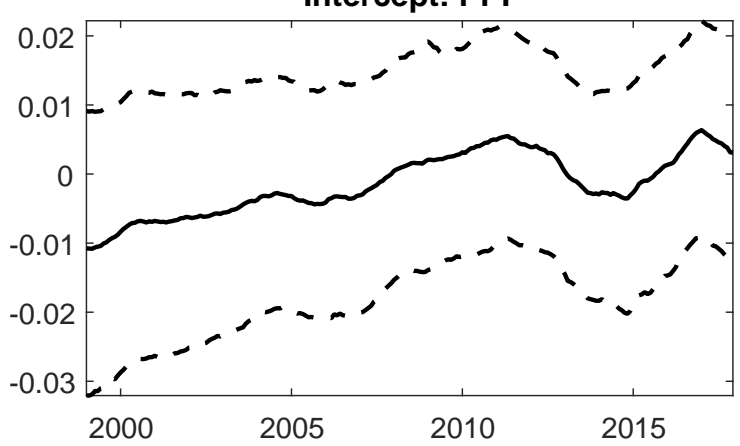

Intercept: IP-G

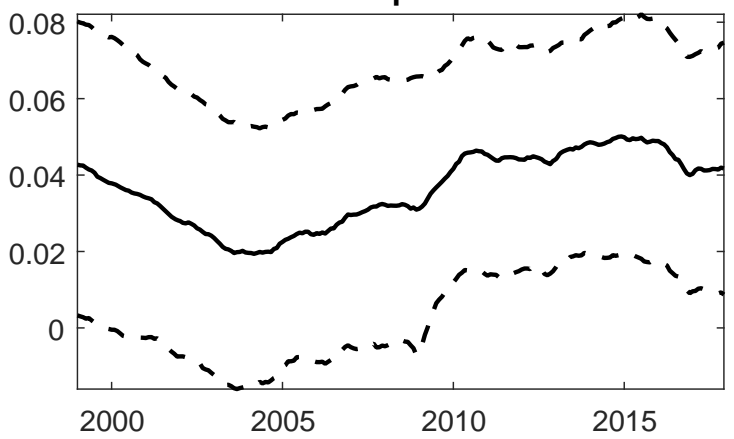

Intercept: CPM

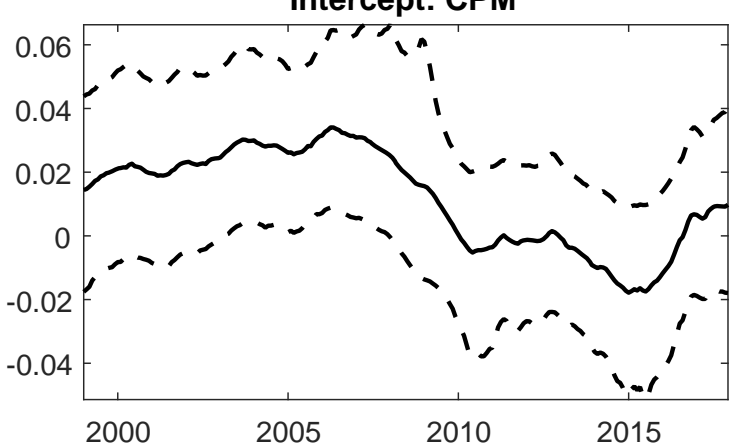

Intercept: EMS

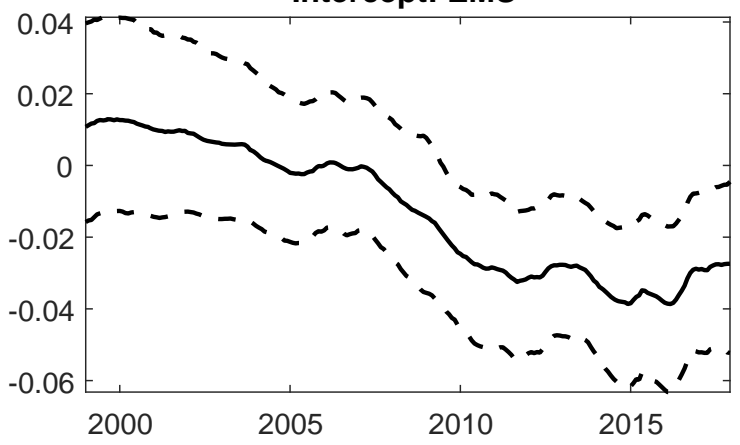

Figure 17: Drift of the median of the intercept term $c_{t}$ over time. Dashed lines indicate $16 \%$ and $84 \%$ confidence intervals.

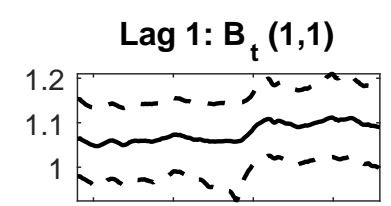

2000200520102015

$\operatorname{Lag} 1: B_{t}(2,1)$

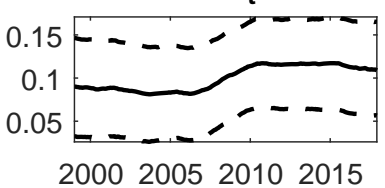

2000200520102015

$\operatorname{Lag} 1: B_{t}(3,1)$

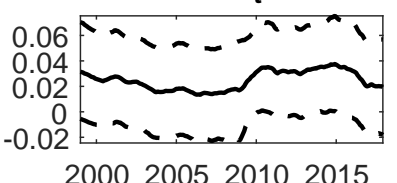

$\operatorname{Lag} 1: B_{t}(4,1)$

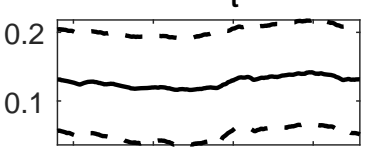

2000200520102015
$\operatorname{Lag} 1: B_{t}(1,2)$

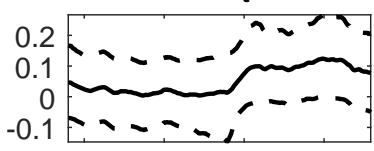

2000200520102015

Lag 1: $B_{t}(2,2)$

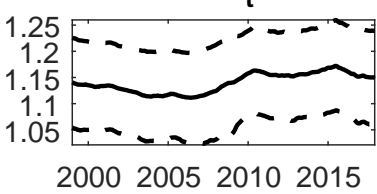

Lag 1: $B_{t}(3,2)$

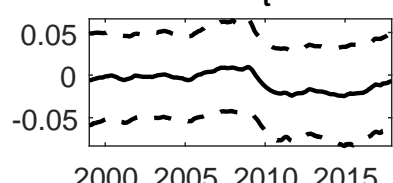

$\operatorname{Lag} 1: B_{t}(4,2)$

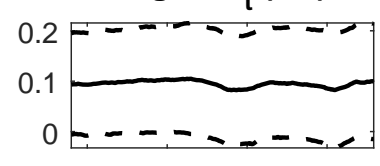

2000200520102015

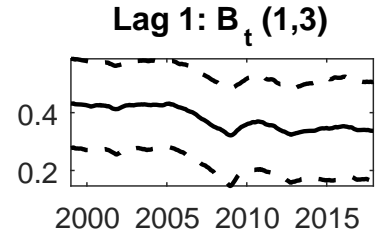

Lag 1: $B_{t}(2,3)$

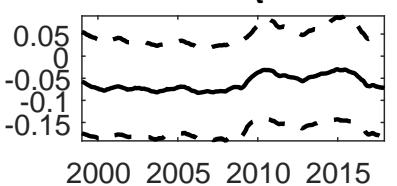

Lag 1: $B_{t}(3,3)$

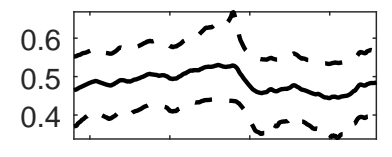

2000200520102015

Lag 1: $B_{t}(4,3)$

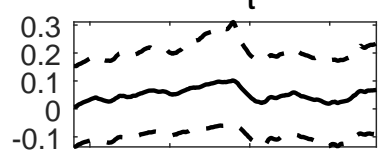

2000200520102015
$\operatorname{Lag} 1: B_{t}(1,4)$

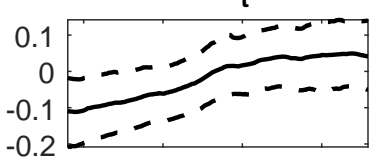

2000200520102015

$\operatorname{Lag} 1: B_{t}(2,4)$

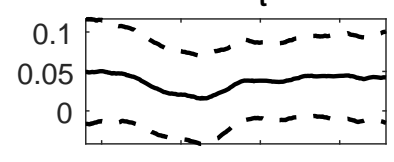

2000200520102015

$\operatorname{Lag} 1$ : $B_{t}(3,4)$

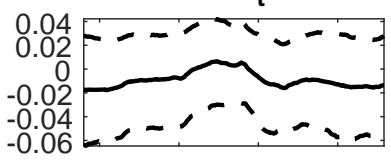

2000200520102015

$\operatorname{Lag} 1: \mathrm{B}_{\mathrm{t}}(4,4)$

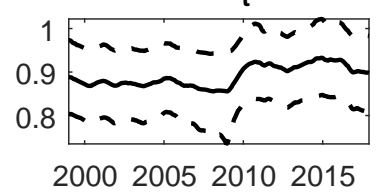

Figure 18: Drift of the median of the autoregressive parameter $B_{1, t}$ over time. Dashed lines indicate $16 \%$ and $84 \%$ confidence intervals. 
Lag 2: $B_{t}(1,1)$

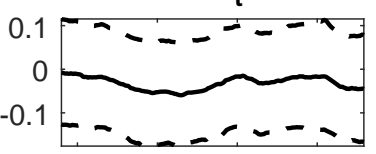

2000200520102015

Lag 2: $B_{t}(2,1)$

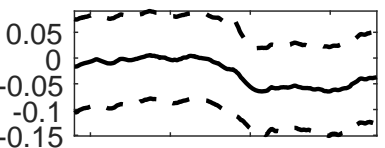

2000200520102015

Lag 2: $B_{t}(3,1)$

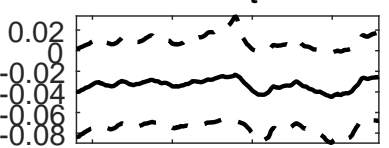

2000200520102015

Lag 2: $B_{t}(4,1)$

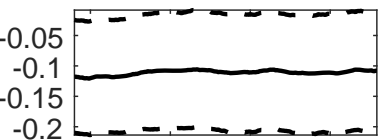

2000200520102015
Lag 2: $B_{t}(1,2)$

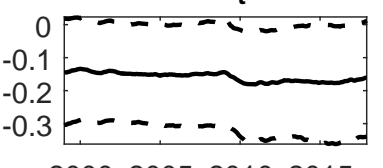

2000200520102015

Lag 2: $B_{t}(2,2)$

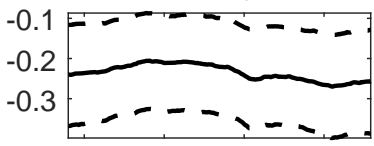

2000200520102015

Lag 2: $B_{t}(3,2)$

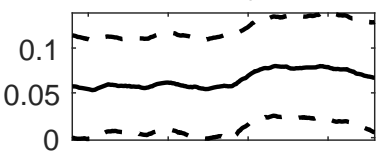

2000200520102015

Lag 2: $B_{t}(4,2)$

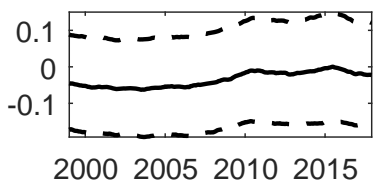

Lag 2: $B_{t}(1,3)$

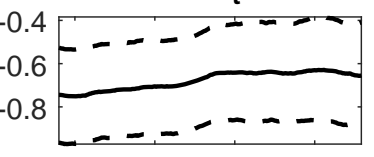

2000200520102015

Lag 2: $B_{t}(2,3)$

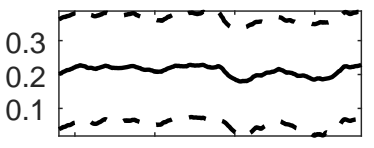

2000200520102015

Lag 2: $B_{t}(3,3)$

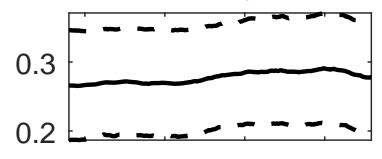

2000200520102015

Lag 2: $B_{t}(4,3)$

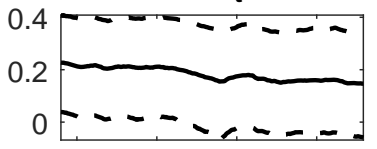

2000200520102015
Lag 2: $B_{t}(1,4)$

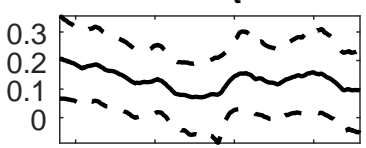

2000200520102015

Lag 2: $B_{t}(2,4)$

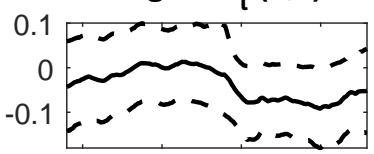

2000200520102015

Lag 2: $B_{t}(3,4)$

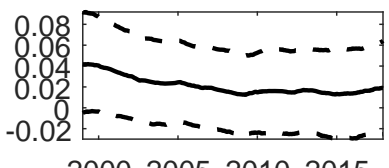

2000200520102015

Lag 2: $B_{t}(4,4)$

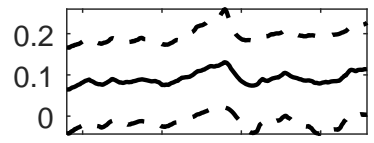

2000200520102015

Figure 19: Drift of the median of the autoregressive parameter $B_{2, t}$ over time. Dashed lines indicate $16 \%$ and $84 \%$ confidence intervals.

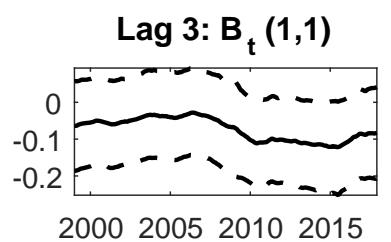

Lag 3: $B_{t}(2,1)$

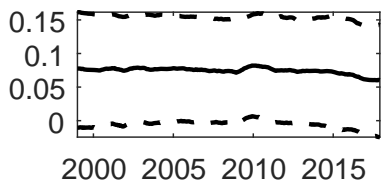

Lag 3: $B_{t}(3,1)$

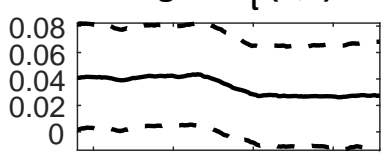

2000200520102015

Lag 3: $B_{t}(4,1)$

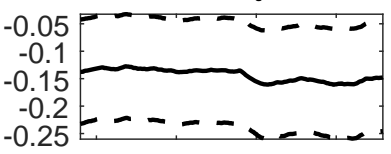

2000200520102015
Lag 3: $B_{t}(1,2)$

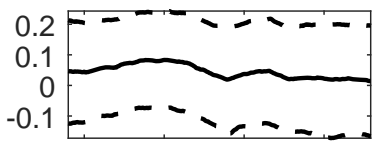

2000200520102015

Lag 3: $B_{t}(2,2)$

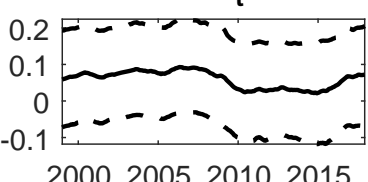

Lag 3: $B_{t}(3,2)$

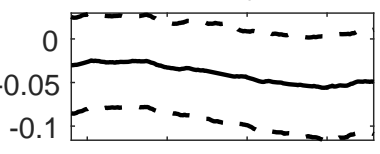

2000200520102015

Lag 3: $B_{t}(4,2)$

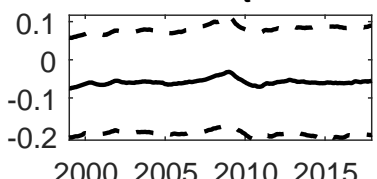

Lag 3: $B_{t}(1,3)$

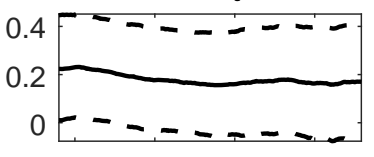

2000200520102015

Lag 3: $B_{t}(2,3)$

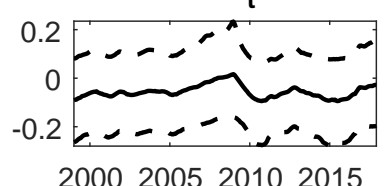

Lag 3: $B_{t}(3,3)$

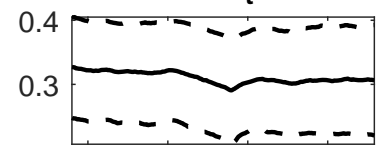

2000200520102015

Lag 3: $B_{t}(4,3)$

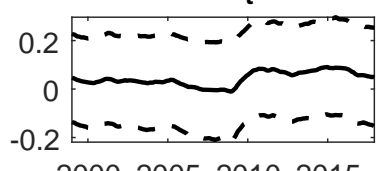

Lag 3: $B_{t}(1,4)$

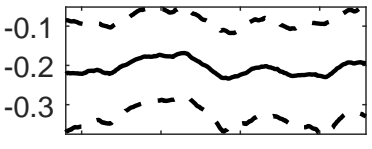

2000200520102015

Lag 3: $B_{t}(2,4)$

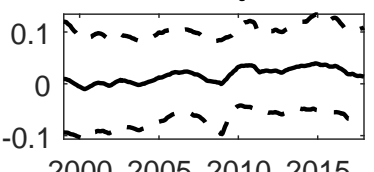

Lag 3: $B_{t}(3,4)$

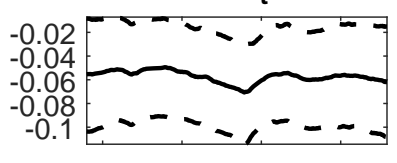

2000200520102015

Lag 3: $B_{t}(4,4)$

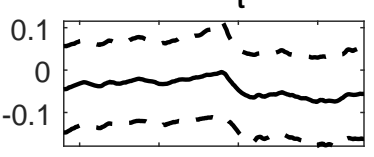

2000200520102015

Figure 20: Drift of the median of the autoregressive parameter $B_{3, t}$ over time. Dashed lines indicate $16 \%$ and $84 \%$ confidence intervals. 


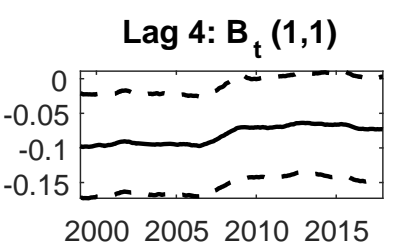

Lag 4: $B_{t}(2,1)$

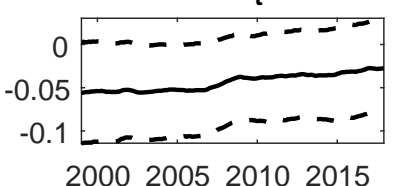

Lag 4: $B_{t}(3,1)$

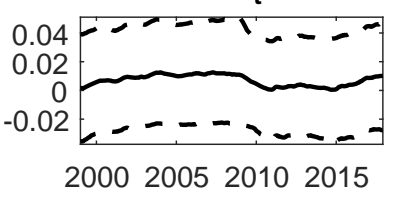

Lag 4: $B_{t}(4,1)$

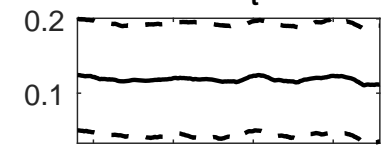

2000200520102015
Lag 4: $B_{t}(1,2)$

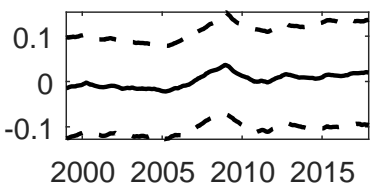

Lag 4: $B_{t}(2,2)$

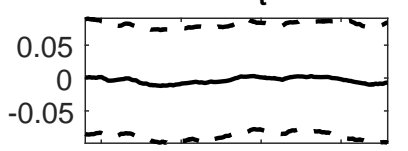

2000200520102015

$\operatorname{Lag} 4: B_{t}(3,2)$

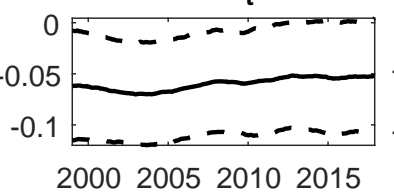

Lag 4: $B_{t}(4,2)$

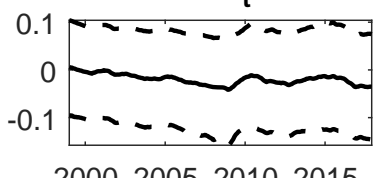

Lag 4: $B_{t}(1,3)$

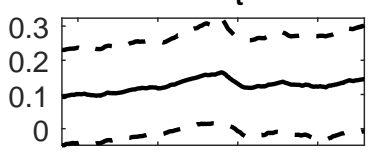

2000200520102015

Lag 4: $B_{t}(2,3)$

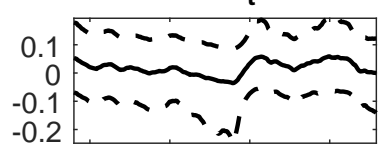

2000200520102015

Lag 4: $B_{t}(3,3)$

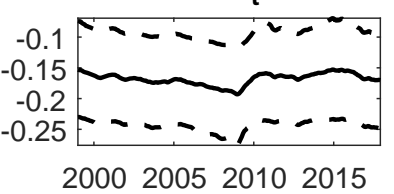

Lag 4: $B_{t}(4,3)$

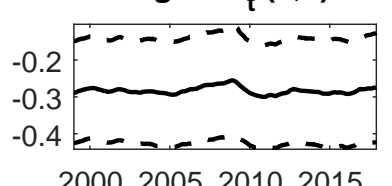

$\operatorname{Lag} 4: B_{t}(1,4)$

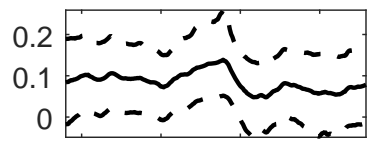

2000200520102015

Lag 4: $B_{t}(2,4)$

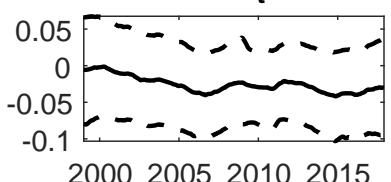

Lag 4: $B_{t}(3,4)$

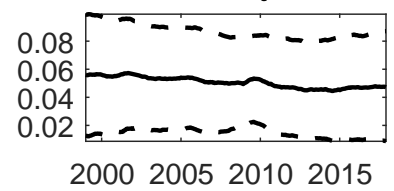

Lag 4: $B_{t}(4,4)$

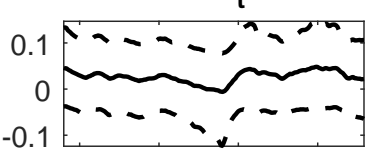

2000200520102015

Figure 21: Drift of the median of the autoregressive parameter $B_{4, t}$ over time. Dashed lines indicate $16 \%$ and $84 \%$ confidence intervals.
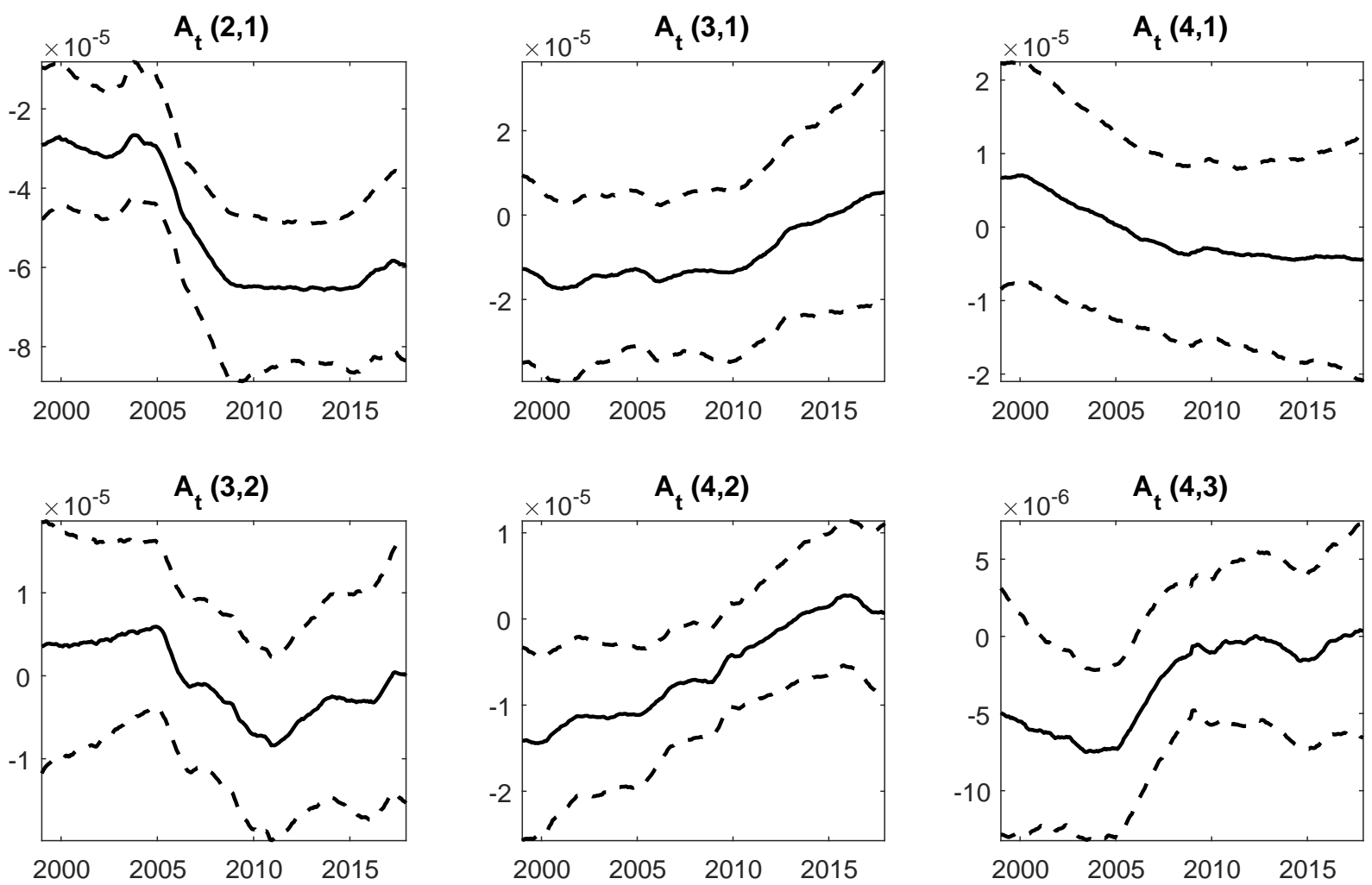

Figure 22: Median of the lower-triangular elements of matrix $A_{t}$ : Evolution of contemporaneous relations of shocks. 